\title{
Federaciones, actividades deportivas y medio natural. Sobre la viabilidad de algunas funciones públicas delegadas
}

\section{Sport federations, sport acttivity, and natural environment: What is new about the viability of delegated public functions}

$$
\text { Ignacio fiménez Soto }
$$

Catedrático de Derecho Administrativo

Director de la Cátedra de Estudios e Investigación en Derecho del Deporte

Universidad de Granada ${ }^{1}$

SUMARIO: I.INTRODUCGIÓN: EL OPORTUNO RECONOGIMIENTO EN LA NUEVA LEY DEL DEPORTE DE ANDALUCÍA Y EN OTRAS COMUNIDADES DE LA AGTIVIDAD DEPORTIVA EN EL MEDIO NATURAL. II. EL FOMENTO DE LA PRÁCTICA DEL DEPORTE EN EL MEDIO NATURAL COMO DESARROLLO SOSTENIBLE. 1. El impulso del deporte en el medio natural a través de títulos habilitantes, además de la licencia deportiva. Una vis expansiva para fortalecer las estructuras deportivas. 2. El compromiso con el desarrollo sostenible. III. LA GESTIÓN DE LOS ESPACIOS NATURALES PROTEGIDOS (ENP) Y EN ESPECIAL LOS INSTRUMENTOS DE ORDENACIÓN. IV. LAS FEDERACIONES DEPORTIVAS COMO AGENTES COLABORADORES DE LA ADMINISTRACIÓN EN MATERIA DE MEDIO AMBIENTE Y SEGURIDAD EN LA PRÁCTICA DEL DEPORTE EN EL MEDIO NATURAL. V. EL GASO GONCRETO DE LOS

\footnotetext{
1 Disertación pronunciada el día 29 de octubre de 2019, en la toma de posesión como Académico Correspondiente de la Real Academia de San Dionisio de Ciencias, Artes y Letras de Jerez de la Frontera (Cádiz).

Trabajo enmarcado dentro del Grupo de Investigación SEJ-459 "Medio Ambiente, Ordenación del Territorio y Energía" (MOE), que dirige el Pr. Dr. Estanislao Arana García, Catedrático de Derecho Administrativo de la Universidad de Granada.

Recibido: 01/11/2019

Aceptado: 08/11/2019
} 
SENDEROS DE USO DEPORTIVO DE ANDALUCÍA: EL DECRETO 67/2018, DE 20 DE MARZO. 1. Del trampantojo legal de la norma a una colaboración intensa entre Administración y Federaciones Deportivas. 2. Naturaleza Jurídica del suelo. VI. LA PRÁCTICA DEPORTIVA DEL ESQUÍ Y SUS ESPEGIALIDADES A TRAVÉS DE LICENGIA O TÍTULOS HABILITANTES. VII. CONSIDERACIONES FINALES. VIII. BIBLIOGRAFÍA.

RESUMEN: El incremento de personas que deciden utilizar el medio natural en sus ratos de ocio, es cada día mayor, destacando entre éstas quienes eligen la práctica deportiva con fines no competitivos, sino de placer y recreación, convirtiéndose en un usuario cualificado, al que la nueva legislación deportiva autonómica, como es el caso de la Ley 5/2016, de 19 de julio, del Deporte de Andalucía, le permite pertenecer a una federación deportiva no solamente con la tradicional licencia federativa, dedicada al deporte de competición oficial, sino también con un título habilitante para los deportistas de ocio. Con esta nueva inclusión de los deportistas en las estructuras federativas, se fortalece el asociacionismo deportivo, por lo que las federaciones deportivas relacionadas con el deporte en el medio natural pueden colaborar en la protección y conservación del medio ambiente, al incorporar estas actividades en el ámbito de las funciones públicas delegadas, asistiendo a una nueva técnica de control administrativo distinta a la de policía, y sí a través de la autorregulación regulada para determinadas actividades y en determinados lugares, destacando por su importancia los Espacios Naturales protegido (ENP). Funciones públicas delegadas que ya están realizados algunas federaciones deportivas, en este caso Montaña y Escalada en la homologación de senderos, a los que nos vamos a referir en el análisis de la posibilidad del ejercicio de la potestad expropiatoria cuando discurren por fincas privadas; igualmente, se realiza un estudio sobre el ejercicio de la potestad disciplinaria en el esquí y sus especialidades a través de la licencia o título habilitante, dentro del compendio de facultades públicas delegadas.

ABSTRACT: The increase of people who decide to use the Protected Natural Spaces (PNE) in their leisure time, is increasing every day, highlighting among those who choose the sport for non-competitive purposes, but for pleasure and recreation, becoming a qualified user, to which the new sports legislation, as in the case of the Law 5/2016, of July 19, of the Sport of Andalusia, allows it to belong to a sports federation, not only with the traditional federative license, dedicated to official competitive sport, but also with an enabling title for leisure athletes. With this new inclusion of athletes in the federative structures, sports associations are strengthened, so sports federations related to sports in the natural environment can collaborate in the protection and conservation of the environment, by incorporating these activities in the 
field of delegated public functions, attending a new administrative control technique different from the police, and through regulated self-regulation for certain activities and in certain places of the PNE.

PALABRAS CLAVE: Actividad deportiva en el medio natural; ámbito competitivo no oficial y recreativo y de ocio; Administración deportiva y Administración ambiental; turismo activo; intervención administrativa: ordenación, planificación y autorregulación regulada en los ENP; Planes Rectores de Uso y Gestión y actividades deportivas de ocio; uso público de los recursos naturales; participación de los ciudadanos; colaboración interadministrativa; licencias deportivas y títulos habilitantes; interacción usuarios-medio natural-Administración, senderos públicos de uso deportivo y ejercicio de expropiación forzosa, viabilidad de potestad disciplinaria en la práctica del esquí y sus especialidades.

KEY WORDS: Sports activity in the natural environment; unofficial competitive and recreational and leisure environment; Sports Administration and Environmental Administration; Active turism; administrative intervention: regulation, planning and regulated self-regulation in the ENP; Master Plans for Use and Management and leisure sports activities; public use of natural resources; participation of citizens; inter-administrative collaboration; sports licenses and qualifying titles; Interaction users-natural medium-Administration.

\section{INTRODUGGIÓN: EL OPORTUNO RECONOCIMIENTO EN LA NUEVA LEY DEL DEPORTE DE ANDALUGÍA Y EN OTRAS COMUNIDADES DE LA ACTIVIDAD DEPORTIVA EN EL MEDIO NATURAL}

Qué duda cabe que la actividad deportiva en el medio natural, como tal, desde una perspectiva estrictamente deportiva y por qué no jurídica, en las últimas décadas, ha estado exenta del protagonismo que le correspondía por su cercanía con la actividad turística y con los componentes medioambientales ${ }^{2}$, debido a que los contornos turísticos y ambientales metafóricamente han abducido a la práctica deportiva en sí; cuando valga la paradoja, este tipo de actividad va adquiriendo un notabilísimo incremento de practicantes en los últimos años.

Un solo ejemplo sirve para corroborar estos planteamientos, como es que ya en el año 2010 la Federación Española de Montaña y Escalada (FEDME) contaba con

2 Tal y como tuvimos la oportunidad de exponer en JIMÉNEZ SOTO, I., "El difícil anclaje jurídico de las actividades deportivas en los espacios naturales protegidos, a través de los instrumentos de ordenación”, en F. BALAGUER CASTELLÓN, y E. ARANA GARCÍA (coord.), libro homenaje al Profesor Rafael Barranco Vela, Civitas Thomson Reuters, Madrid, 2014, Vol. II, pp. 1990-2012. 
87.147 licencias y 1759 clubes y, 7 años más tarde, esto es 2017, los datos son 237825 licencias y 2748 clubes, (datos WEB Consejo Superior de Deportes) que la sitúan entre las Federaciones deportivas españolas con mayor número de deportistas, en concreto en el puesto número 5, justo detrás de fútbol, baloncesto, caza y golf. Por lo que respecta a Andalucía, la Federación Andaluza de Montaña y Deportes de Escalada (FADME) presenta una muy meritoria factura, pasando de 8.158 licencias en 2010 a 39392 en 2017 y 323 clubes, notabilísimo incremento que, tiene entre sus razones, el aumento considerable de personas que hacen del medio natural su práctica deportiva preferida, consecuencia del boom del senderismo, además de las nuevas modalidades como las carreras de montaña o la bicicleta de montaña, no sólo en el ámbito competitivo oficial, sino competitivo no oficial y recreativo o de ocio.

Así pues, son numerosos los ciudadanos que practican estos deportes al margen del tejido federativo, por meras razones de salud o placer, o ambas a la vez, sin olvidar el elemento sociológico de indudable valor, como es el de ser modalidades deportivas que puede practicar toda la familia en su conjunto, algo difícil de encontrar en otros deportes, y a un precio muy asequible a los bolsillos familiares.

A este tipo de practicantes deportivos, tanto los no participantes en competiciones oficiales como los deportistas de ocio, se refieren las nuevas Leyes del deporte autonómicas, como es el caso de la Ley 5/2016, de 19 de julio, del Deporte en Andalucía (art. 35), en un intento de dar cobertura jurídica a los numerosos deportistas, que no se encuentran ubicados en el tradicional anclaje federativo del deporte de competición oficial.

$\mathrm{Y}$ entre estos deportistas, abundan los que prefieren como modalidad o especialidad deportiva, aquellas actividades que se realizan en el entorno natural, llegando en algunas ocasiones a concentrarse miles de participantes, por el mero hecho de poder realizar la prueba, siendo numerosos ejemplos los que podemos citar, no sólo en España: en las carreras de esquí nórdico, es el caso de la más famosa que se celebra en Suecia en la Vasoloppet que aglutina a 60.000 esquiadores de 40 países, o en los ya afamados $101 \mathrm{~km}$ de la Legión de Ronda, que comenzó en 1995 con 400 participantes y en 2017 ya tuvo que limitar la inscripción a 7500 participantes en esta carrera y bicicleta de montaña, manifestaciones deportivas donde efectivamente el componente competitivo no es el aliciente principal.

Pero lo verdaderamente importante, independientemente de los planteamientos que al respecto se puedan hacer, es el acierto que tiene la nueva legislación deportiva en las Comunidades Autónomas por incluir entre sus preceptos la actividad deportiva en el medio natural, ya que esta regulación no la encontramos en el ámbito estatal de la Ley 10/90, de 15 de octubre, del Deporte; y sí, en las leyes posteriores de carácter autonómico, donde se ha producido una notabilísima evolución al respecto, 
basta ver la anterior ley andaluza, Ley 6/1998, de 14 de diciembre, del Deporte en Andalucía, donde solamente podíamos encontrar una muy tenue referencia en los principios rectores del artículo 2. J): "El respeto al medio ambiente y la protección del medio natural, prevaleciendo los usos comunes sobre los especiales y privativos".

Ahora, con la nueva Ley 5/2016, la intensidad es muchísimo mayor, pues si bien continua con su inclusión entre los principios rectores, es decir, entre las pautas de actuación que establece la Ley a los poderes públicos, podemos encontrar referencias muy marcadas en el protagonismo que adquieren estas actividades, es el caso del artículo 5.ñ): "el respeto y protección al medio ambiente, aprovechando el medio natural para aquellas actividades y competiciones deportivas y de tiempo libro más adecuadas".

Es llamativo como el legislador no se limita a las competiciones deportivas, sino también extiende la actuación pública a las "actividades de tiempo libre", que habrá que anudar con la expedición de otros títulos habilitantes que permiten participar en competiciones no oficiales y en actividades de ocio (art. 25.4), junto al fomento del deporte de ocio , cuando el artículo 28.1 dice: "La Consejería competente en materia de deporte fomentará el deporte de ocio mediante el desarrollo de una política deportiva a través de la planificación y programación de la oferta de actividades deportivas de tiempo libre y de recreación, buscando estándares de calidad y excelencia”.

Constituyendo una de las aportaciones más interesantes en este ámbito, la que realiza la norma andaluza en el artículo 10, dedicado a la actividad deportiva en el medio natural, donde junto a la obligación de fomentar por parte de los poderes públicos la práctica del deporte en el medio natural de una manera sostenible (art.10.1), otorga al medio natural la consideración de instalación deportiva no convencional ${ }^{3}$ cuando se utilice para la práctica deportiva (art.10.3); así como la colaboración de las consejerías competentes en materia de deporte, turismo y medio ambiente, para favorecer la práctica del deporte en el medio natural como elemento generador de actividad turística (art.10.6).

Sin embargo, de ahí la importancia de la nueva Ley, en el caso concreto de las actividades deportivas en el medio natural, la Administración deportiva y por su extensión los operadores deportivos, como acabamos de exponer, con el nuevo marco autonómico del deporte en Andalucía, a través de un artículo 10, vienen a situar a la actividad deportiva en un primer plano.

3 Se da la paradoja que, en el ámbito estatal, como advertimos en la timorata Ley 10/90 del Deporte a penas se menciona la actividad deportiva en el medio natural; sin embargo, en el Censo de Instalaciones Deportivas del Consejo Superior de Deportes (CNID-2005, CNID-2010) se encuentran numerosos espacios naturales en su consideración de instalaciones deportivas, si bien es cierto que estos datos los ofrecen las Comunidades Autónomas. 
Asimismo, otro buen ejemplo lo encontramos en Aragón, donde en la anterior Ley 4/1993, de 14 de marzo del Deporte de Aragón, al describir las actuaciones de coordinación de las Administraciones públicas, establecía en su artículo 3.l): "Proteger las instalaciones naturales susceptibles de aprovechamiento deportivo", para a continuación, en el artículo 44, determinar que será necesario contar con la pertinente autorización, cuando se trate de usos deportivos en las instalaciones calificadas de carácter natural, que sean de titularidad o cuya gestión esté encomendada a la Comunidad Autónoma, pudiendo restringirse temporalmente por motivos de seguridad y protección del medio ambiente.

Hoy día la actual Ley 16/2018, de 4 de diciembre, de la actividad física y el deporte de Aragón, incide en el principio rector en el artículo 4.g): "La promoción de la adecuada utilización del medio natural, para la práctica de la actividad física y deportiva y su compatibilización con la protección del medio ambiente", y además le presta una especial atención en el Título de las instalaciones deportivas; por un lado, al incluir en las instalaciones, equipamientos y espacios deportivos (art.59.c) el: " Espacio deportivo no convencional: aquel situado en el medio urbano o natural, no diseñado específicamente para la práctica deportiva y que es utilizado para el desarrollo de actividad fisica y deportiva". De otro lado, cuando se determina la utilización de las instalaciones deportivas no convencionales de carácter natural y artificial, nos encontramos con las autorizaciones administrativas correspondientes para su disposición con carácter deportivo, así como de la obligatoriedad de suscribir un seguro específico para este tipo de práctica deportiva (art.69).

El ejemplo en las Islas Canarias, podemos considerarlo como muy gráfico del aumento que tienen estas actividades para el legislador, pues en la Ley 8/1997, de 9 de julio, Canaria del Deporte, apenas se encontraba regulación al respecto, tan sólo en las líneas generales de actuación el artículo 2.h) dispone: "Políticas que se adapten a las limitaciones de los recursos naturales y a los principios de desarrollo sostenible y de respeto a los valores de naturaleza". Esta nimia referencia de la legislación canaria, ya de por si sorprendía, pues el archipiélago cuenta con ser una de las zonas de la Unión Europea con más Espacios Naturales Protegidos, de los que sobresalen 4 Parques Nacionales: Teide (Tenerife), Garajonay (Gomera), Caldera de Taburiente (La Palma) y Timanfaya (Lanzarote),y 11 Parques Naturales.

Por el contrario, la nueva Ley 1/2019, de 30 de enero de la Actividad física y el deporte de Canarias, incluye prácticamente la misma redacción en los principios rectores, que la anterior, pero en el nuevo artículo 3.g) se añade: “. . y y la empatía hacía los animales silvestres, domésticos y de compañía”; creemos interesante, antes de seguir con la inclusión normativa en el deporte canario, recalcar la importancia que tienen los "deportes autónomos y tradicionales", cuyas modalidades, en estos momentos, son: 
arrastre canario, bola canaria, carros de madera canario, juego de palo canario, levantamiento de arado canario, levantamiento y pulseo de piedra canario, pelota a mano canaria, vela latina canaria (art.27), por lo que sin ser especialistas en estas práctica deportivas, es fácil intuir que buena parte de éstos se desarrollan en el medio natural ${ }^{4}$, luego implícitamente la regulación y acogimiento de éstos por la Ley, es un signo más de la importancia de la actividad deportiva en el medio natural.

Ciñéndonos en aspectos más concretos, en el Censo de Instalaciones Deportivas Canarias, se incluyen los espacios naturales (art.51.2); en la tipología de los Espacios Deportivos, nos encontramos con las Áreas de Actividad (art. 52.1.c): "espacios no estrictamente deportivos, como son las infraestructuras o los espacios naturales incluidos los marítimos...son áreas de actividad, entre otras, las bahías, los senderos, las playas y el espacio aéreo", concretando que la Red Básica de Instalaciones Deportivas incluirá los espacios deportivos convencionales o no (art. 52.3).

Si ya es verdaderamente importante la regulación, sobre todo por los deportes autóctonos y tradicionales, podemos destacar de relevante el artículo 54 destinado a los Espacios Deportivos para el deporte en el medio natural, donde ya en su apartado $1^{\circ}$, los clasifica de acuáticos, terrestres y aéreos; y en el apartado $2^{\circ}$ determina que las Administraciones públicas canarias promoverán las condiciones favorables para la práctica de estos deportes, de forma libre y espontánea, en el medio natural, reglamentando su uso y disfrute, con las disponibilidades presupuestarias para que éstos se desarrollen en las condiciones más óptimas y seguras.

Siguiendo con ejemplos, la Ley 2/1994, de 29 de diciembre, del Deporte en Asturias nos conduce al artículo 3.h) donde los poderes públicos del Principado de Asturias garantizarán el acceso de todos los ciudadanos a la práctica del deporte de acuerdo con las siguientes líneas de actuación: "Promover la consideración del medio natural como espacio deportivo, haciendo compatible el uso deportivo con la protección del medio ambiente"; de esta regulación, pasamos al Anteproyecto de Ley de Actividad Física y Deporte (texto de agosto de 2018), donde podemos apreciar un giro notable en un texto legal que potencia estas actividades deportivas. Así, vemos cuando en el artículo 3.f) del Anteproyecto, incluido en los principios rectores, mantiene prácticamente el contenido de la Ley vigente, si bien aporta un añadido interesante de gran utilidad para los deportistas en el medio natural, como es: "... así como la existencia de información actualizada de la regulación, condiciones y lugares donde se puede realizar la práctica del deporte en el medio natural", decimos de gran utilidad, puesto que uno de los grandes inconvenientes que se tienen para practicar estas actividades, suele ser la falta de información

4 Sobre la importancia del medio natural en la actividad deportiva, se puede ver en el trabajo del profesor y presidente de la Federación Canaria de Surf LOBO RODRIGO, A., la ordenación y gestión de playas: especial referencia a los usos turístico-deportivos, Tirant Lo Blanch, Valencia, 2016. 
de pistas, senderos, autorizaciones, lugares, etc., que constituyen muchas veces un hándicap muy negativo para el deportista, incluso con enfrentamientos y sanciones con los agentes forestales o medioambientales, el Seprona de la Guardia Civil, al estar realizando la actividad deportiva, por ejemplo bicicleta de montaña por una zona prohibida, sin que se haya tenido conocimiento por falta de información o cuando ésta se presta de forma deficiente.

También, siguiendo con la tendencia de considerar el espacio natural como instalación deportiva, el artículo 22.2 del Anteproyecto presenta la siguiente regulación: "Formarán parte del censo de instalaciones además de las deportivas convencionales, los mapas de orientación, circuitos urbanos de ejercicio físico, parques que contengan espacios destinados a la práctica de la actividad física y el deporte, recorridos de bicicleta de montaña y rutas por senderos", todo ello fortalecido, por la propias características de estas actividades, con la opción de la licencia deportiva o el título habilitante, puesto tal y como regula el artículo 68.4: " ...Las federaciones deportivas asturianas podrán expedir otras habilitaciones administrativas de temporada o de dia, que permitan participar en competiciones y actividades ordenadas que no tengan la calificación de oficiales".

Regulación autonómica que, como exponemos a continuación, las nuevas orientaciones legales, empobrece la timorata regulación que hace la Ley estatal al deporte en el medio natural, donde es tan superficial, que apenas merece comentario, tal como lo encontramos en el artículo 8. q) de las competencias del Consejo Superior de Deportes: "Colaborar en materia de medio ambiente y defensa de la naturaleza con otros organismos públicos con competencias en ello y con las federaciones, especialmente relacionados con aquellos", y nada más, un brindis al sol en un día nublado.

Es más, el Anteproyecto de Ley del Deporte, aprobado por el Consejo de Ministros el 31 de enero de 2019, al que se le han presentado 151 enmiendas, se mantiene en la misma línea, con algunas excepciones que ahora expondremos, de no darle a la actividad deportiva en el medio natural el lugar que le corresponde, máxime cuando el texto normativo trae su causa en el artículo 43.3 de la Constitución, el que habla del fomento de la educación física y el deporte, así como la adecuada utilización del ocio, eso sí, en el marco de la Administración General del Estado.

Se justifica su competencia normativa en el artículo 149.1.1 $1^{\text {a }}$ de la CE, que no es otro que aquel que establece como competencia exclusiva del Estado, la regulación de las condiciones básicas que garantizan la igualdad de todos los españoles, por lo que se ha perdido una excelente oportunidad, de haber incluido un articulado específico de las actividades deportivas en el medio natural, al menos en cuanto a la regulación de los "derechos de las personas deportistas", como hubiera sido el derecho preferente a la realización de actividades deportivas en los Espacios Naturales Protegidos en las mismas condiciones de igualdad en todo el Estado, lo que conlleva- 
ría el uso y disfrute, así como la utilización de los refugios de montaña, algo que desgraciadamente hemos visto, como algunas federaciones autonómicas no reconocían la igualdad de trato en función de la naturaleza de la tarjeta federativa, por citar un ejemplo a la hora de utilizar los refugios.

No obstante, hay que decir que en el Anteproyecto, la futura ley también acoge la práctica deportiva fuera del modelo de la competición oficial, como hacía hasta ahora, y así el artículo 38 está dedicado a las personas deportistas en la competición o en la práctica deportiva no oficial en el ámbito de las federaciones deportivas españolas, pero limitándose esta regulación, a que el Consejo Superior de Deportes, podrá establecer condiciones específicas de protección de la salud, incluso podrá establecerlo como requisitos de admisión en la federación o en los organizaciones de actividades no oficiales.

Así las cosas, del Anteproyecto de Ley estatal del Deporte, si bien presenta mayor contenido al respecto, no es menos cierto que se trata de regulaciones aisladas que se ciernen en torno a la protección del medio ambiente, pero no a la práctica deportiva y al deportista, como hubiera sido de esperar, por lo que se mantiene en la línea anterior de los años 90, cuando estas actividades estaban en pañales.

Esto se aprecia en los principios rectores, los cuales marcan la orientación al poder público, con la siguiente literalidad en el artículo 3.1: "El desarrollo de la actividad física y el deporte en condiciones compatibles y respetuosas con el medio ambiente, con la protección del medio natural y el entorno urbano, así como la seguridad de las personas"; más llamativo, siguiendo en esta afán proteccionista que, entre las competencias del Consejo Superior de Deportes, tengamos un lacónico artículo 13.u), que es común a cualquier Administración pública en relación con el medio ambiente, luego aquí poco aporta la Administración deportiva, al establecer: "Colaborar con el resto de las Administraciones Públicas en la adopción de medidas que aseguren la sostenibilidad de la actividad deportiva en el medio ambiente, asi como en el entorno urbano y natural".

En este olvido de derechos, curiosamente si aparece una mención concreta en el apartado de deberes de las personas deportistas, con lo cual asistimos a un hecho algo insólito como es que una ley no reconozca derechos específicos y si deberes específicos, es más; lo usual, es al revés como sucede con las leyes de Educación, Universidades, etc., pues no, en este anteproyecto nos encontramos con dos deberes, incidentales en el deportista en el medio natural: artículo 23.1.c:"Prácticar la actividad física y el deporte en las condiciones más respetuosas posibles con el medio natural, el medio ambiente y el entorno natural y urbano". Alguien podrá alegar que se refiere a todos los deportistas, pero qué duda cabe que es una obligación más intensa a los deportistas en el medio natural, verdad no es lo mismo un jugador de tenis de mesa que un montañero escalando una vía, al igual que podemos encontrar en el artículo 23.1.e): "Hacer uso racio- 
nal y adecuado de los bienes de dominio público, de las infraestructuras e instalaciones deportivas y servicios públicos" recordamos que, entre los bienes de dominio público, tenemos los caminos, parques, puentes, obras públicas, montes catalogados, etc., y todos aquellos que podemos encontrar en la abundante legislación al respecto ${ }^{5}$.

Por último, como novedad, introduce el anteproyecto tras la creación de la Conferencia Sectorial del Deporte, un artículo dedicado a la actividad concertada entre las federaciones deportivas y las Comunidades Autónomas, en concreto el artículo 98.1 si bien limitado al uso de la competición: " Cuando en la realización de una competición deportiva sean precisas habilitaciones, permisos o autorizaciones en materia de medio ambiente, dominio público u otras similares, la Conferencia Sectorial del Deporte podrá establecer un sistema previo de participación en la elaboración de calendarios deportivos en los que se incluyan dichas pruebas".

Así pues, creemos que no es exagerada decir como conclusión: que las actividades deportivas en la naturaleza han estado huérfanas en el Ordenamiento Jurídico Deportivo, hasta la aparición de la nueva legislación deportiva autonómica, ubicándose mientras tanto en normas jurídicas turísticas y ambientales principalmente.

Afirmación que, podemos corroborar, con un breve recorrido histórico, no sólo con el Decreto de Turismo Activo de Andalucía ${ }^{6}$, sino con otros ejemplos muy relevantes, como fue el pionero Decreto 81/1991, de 25 de marzo, del Departamento de Comercio, Consumo y Turismo, de Cataluña sobre los requisitos que deben reunir las empresas dedicadas a la organización de actividades deportivas de recreo y turísticas de aventura, y por Orden de 10 de abril de 1991 se especifican estas actividades: parapente, bicicleta de montaña, descenso de barrancos, piragüismo, marcha a caballo, etc., sustituido por el Decreto 56/2003, de las Consejería de Cultura y de Trabajo, Industria, Comercio y Turismo sobre la regulación de las actividades

5 Véase Ley 7/1985, de 2 de abril, reguladora de las Bases de Régimen Local, Ley 33/2003, de 3 de noviembre, del Patrimonio de las Administraciones Públicas; Ley 43/2003, de 21 de noviembre, de Montes, modificada por la Ley 21/2015, de 20 de julio....

6 De muy interesante podemos considerar con ocasión del Decreto andaluz, en relación a las actividades de turismo activo, la aportación de la Ley 1/2019, de la Actividad Física y el Deporte de Canarias, donde en su artículo 22 que lleva como rubrica "actividades deportivas con riesgo intrínseco", en las que por razón del riesgo o del tipo de espacios en el que se desarrollan, requiere una concreta habilitación, acreditación o cualificación para su práctica. Pues bien, amparándose en dicho artículo la Resolución de 12 de julio de 2012, por la que se da publicidad al texto actualizado del Texto Refundido de las disposiciones vigentes, en materia de tasas y precios públicos de la Comunidad Autónoma de Canarias, dispone en el Título XIII sobre tasas por la prestación de determinados servicios de búsqueda, rescate y salvamentos realizados, por el grupo de emergencias y salvamento de la comunidad autónoma, art. 171.1 apartado a) que dicha tasa siempre se sufragará, sea cual sea la situación, cuando se trate de una serie de deportes o actividades peligrosas, donde se enumeran las tradicionales que componen en el denominado turismo activo: descenso de cañones, barrancos, marchas, turismo ecuestre, bicicleta de montaña, escalada, espeleología, paracaidismo, vuelo de ultraligeros... 
físico-deportivas en el medio natural; o el Decreto del Departamento de Cultura y Turismo de la Diputación General de Aragón 146/2000, de 26 de julio que regula el ejercicio y actuación de las empresas dedicadas a la prestación de servicios de turismo activo y de aventura; el Decreto de la Consejería de Industria, Comercio y Turismo del Principado de Asturias 92/2002.

Sorprende pues que, teniendo en cuenta su incidencia en el sistema deportivo, al ser de gran magnitud, no hayan tenido su correspondiente espacio normativo en la legislación deportiva, máxime cuando muy buena parte del denominado "deporte para todos", "deporte en edad escolar", "deporte recreación”, etc., se desarrollan en la naturaleza, como podemos apreciar en las numerosas ofertas de las Concejalías de Deportes, Patronatos Municipales de Deportes, en los Servicios de Deportes de las Diputaciones Provinciales o en la actividad deportiva de las Universidades.

Por lo que es de esperar que las normas reglamentarias que desarrollen la nueva legislación autonómica, vayan en la línea de darle el protagonismo a los operadores deportivos que estos requieren en el medio natural.

Esta ausencia de liderazgo, insistimos esperamos comience a subsanarse, obedece a numerosas razones que sintéticamente podemos apreciar: en primer lugar, en el mal llamado "turismo activo" que ha relegado a un segundo plano los elementos sustantivos del deporte, a favor de los elementos turísticos, concepto que se acuña en el Decreto andaluz 20/2002, de 29 de enero, de turismo en el medio rural y turismo activo, al que la Ley de Turismo de Andalucía, Ley 13/2011, de 23 de diciembre, viene a reforzar y ampliar este concepto, nada más y nada menos, incluyendo estas actividades como servicios turísticos, que es lo mismo que decir actividades sujetas a ordenación y regulación de estos servicios por la Administración de la Junta de Andalucía que, al estar incluidos en la parcela del turismo, obviamente recae en la Administración turística.

Aunque el término "turismo activo" ya la literatura especializada ha dado buena cuenta de su dificulta de consenso, "turismo alternativo", "turismo de aventura", "actividades turístico-deportivas en la naturaleza", etc 7 ; por nuestra parte, hemos apostado por el de "turismo deportivo", término, el de activo, que se quiso utilizar para no confundirlo con el de "turismo del deporte" que es totalmente distinto, pues éste lo vamos a definir como aquella actividad turística que tiene por objeto asistir o presenciar un evento deportivo, como sucede cuando un español viaja a Paris para asistir al Internacional de Tenis "Roland Garros"; por el contrario, cuando la actividad exige

\footnotetext{
7 De esta problemática da buena cuenta de ella PORRAS LIMA, F., en "Derecho Deportivo y Derecho turístico: surgimiento, desarrollo y consolidación del turismo activo en España”, en I. JIMÉNEZ SOTO, y E. ARANA GARCÍA, (directores), El Derecho Deportivo en España 1975-2005, Consejería de Turismo y Deporte de la Junta de Andalucía, Sevilla, 2005, pp.317-348.
} 
un desplazamiento al lugar distinto de residencia para realizar una práctica deportiva, cualquiera de ellas, jugar al Golf en Marbella o cazar en la Sierra de Cazorla estaremos en presencia de turismo deportivo, por cierto modalidades deportivas en el medio natural que no están incluidas en el concepto actual de turismo activo, por lo que podremos considerar que el turismo deportivo es la modalidad, y cuando la práctica deportiva requiere cierto riesgo y destreza estaremos en presencia de una especialidad del turismo deportivo, al que podremos denominar turismo activo ${ }^{8}$.

En segundo lugar, consecuencia del indudable protagonismo de la Administración turística, es el papel desempeñado por la Administración deportiva, que lejos de requerir su protagonismo ha estado en un laissez fair laissez passer, pues si la legislación estatal fue verdaderamente parca, como hemos visto en el papel del CSD, la Administración autonómica en general, la andaluza en particular, no le iba a ir a la zaga, con un lacónico texto dentro de los principios rectores, destinado al respecto al medio ambiente y la protección del medio natural (art. 2.j de la Ley 6/1998).

Con lo que podemos considerar prácticamente inexistentes, las iniciativas por promover el deporte en el medio natural, más allá de las limitadas actuaciones de las federaciones deportivas o de las iniciativas muy meritoria de la Administración local y la de los servicios deportivos de las Universidades, con su programación en el deporte en el medio natural, principalmente senderismo, escalada, esquí y actividades náuticas.

En tercer lugar, corolario a todo lo expuesto, es el predominio de la legislación ambiental, como podemos apreciar en la Orden conjunta de la Consejería de Turismo y Deporte y de la Consejería de Medio Ambiente de la Junta de Andalucía, de 20 de marzo de 2003, por la que se establecen las obligaciones y condiciones medioambientales para la práctica de turismo activo.

Preminencia que, en buena medida, viene justificado por el interés público en la protección del medio ambiente, pero ello no obsta que, en el afán protector, siempre lo hemos aplaudido, nos encontremos con normas como el Decreto 15/2011, de 1 de febrero, de la Consejería de Medio Ambiente, por el que se establece el régimen general de planificación de los usos y actividades en los parques naturales (art.8.4) por cierto anulado en varias sentencias del Tribunal Superior de Justicia de Andalucía y confirmadas por el Tribunal Supremo (STS 3 de julio de 2015 y 16 de febrero 2016), y en particular el Decreto 238/2011, de 12 de julio, sobre la ordenación y gestión de Sierra Nevada, que determina una serie de prohibiciones en materia de bicicletas de montaña en veredas y senderos, excepto en pistas forestales, donde perfectamente se

8 A ello nos hemos referido en otros trabajos con más detenimiento como en JIMÉNEZ SOTO, I., La Configuración jurídica del deporte en el medio natural, relaciones con el turismo, el desarrollo sostenible y la ordenación del territorio", Reus, Madrid, pp.30-48; o JIMÉNEZ SOTO, I., "Actividad deportiva en el medio natural", en A. MILLÁN GARRIDO, A, Comentarios a la nueva Ley del Deporte de Andalucía (director) Reus, Madrid, pp. 156-168. 
podría haber regulado su uso, a través de horarios, número de permisos, alternancia de días, establecimiento de una tasa, etc.

En definitiva todo menos prohibir, por el contrario sí permitir un uso compatible con el medio ambiente, en definitiva se utiliza la técnica de la prohibición en vez de la regulación; apuesta ésta última que, será el núcleo central de esta aportación, por cuanto las entidades deportivas -federaciones deportivas - pueden contribuir de manera considerable a la ordenación de estas actividades, coadyuvando con la Administración en las actuaciones de control, mediante las técnicas regulatorias, incluida la autorregulación regulada ${ }^{9}$, como una función más delegada por la Administración, tal y como permite la legislación deportiva, tanto a nivel estatal en la Ley 10/90 donde el artículo 30.2 establece que las federaciones deportivas españolas, además de sus propias atribuciones, ejerce, por delegación, funciones públicas de carácter administrativo, actuando en este caso como agentes colaboradores de la Administración; o a nivel autonómico en la Ley andaluza que repite en su artículo 57.2 el mismo concepto al hablar de su naturaleza.

Si bien, entre las funciones de las federaciones deportivas andaluzas, queremos matizar la precisión que nos encontramos en el artículo 60.2: "...ejercerán por delegación, bajo los criterios y tutela de la Consejería competente en materia de deporte...", y entre su listado, nos encontramos como cláusula de cierre el apartado g) "cualquier otra que se determine reglamentariamente".

Una consecuencia más de este predominio, lo apreciamos en los órganos de gestión y participación en los Espacios Naturales Protegidos (ENP) que, como sabemos, son los lugares más emblemáticos para la realización de la actividades en el medio natural, donde ya reclama su protagonismo la Administración deportiva en la Ley 5/2016, al decir que el medio natural tendrá la consideración de instalación deportiva no convencional cuando se utilice para estas prácticas (art.4.ñ y 10.3); por lo tanto, tal calificación posibilita que estos espacios estén sujetos a la propia ordenación de las instalaciones deportivas, que corresponde a la Consejería competente en materia deporte (art. 73).

Adquiriendo, de esta forma, un papel importantísimo la colaboración entre la Administración autonómica y la Administración local para favorecer la existencia de información de la regulación, condiciones y lugares donde se puede desarrollar la práctica deportiva en el medio natural (art.10.5), como sucede con uno de los elementos clave para la realización de estas actividades en los senderos ${ }^{10}$, no sólo para la

9 ESTEVE PARDO, J., Lecciones de Derecho Administrativo, (octava edición), Marcial Pons, Madrid, 2018, pp. 83-87.

10 NASARRE SARMIENTO, JM., Senderismo 100 hitos normativos para pensar, Desnivel, Madrid, 2016. Obra de obligada lectura para comprender el significado y alcance actual de los senderos de uso deportivo. 
práctica del senderismo, sino también porque muchas veces son la vía para acceder a la práctica de numerosas actividades en el medio natural, convirtiéndose la información en un elemento muy valioso para el deportista.

Pues bien, la realización de cualquier actividad en los ENP, está en función de dos instrumentos de indudable importancia el Plan de Ordenación de los Recursos (PORN) y el Plan Rector de Uso Gestión (PRUG) que, en definitiva, son los que nos permiten, limitan, modelan o prohíben la práctica deportiva entre otras actividades.

Instrumentos de ordenación donde tienen mucho que ver los órganos de participación y gestión; en el caso de Andalucía el Decreto 239/1997, de 115 de octubre, por el que se regula la constitución y funciones de las Juntas Rectoras de los Parques Naturales, vemos el escaso protagonismo que tienen los agentes deportivos, cuando al menos, en algunas zonas, constituyen el mayor número de usuarios, y su representación sobre una media de cuarenta representantes de los municipios, de las asociaciones de vecinos, diputaciones, etc., sólo alcanza a tres representantes de la Federaciones deportivas andaluzas, entre ellas Caza, Pesca y Montañismo.

Igualmente, en los Consejos de Participación que asumen las funciones de los Patronatos de los Parques Nacionales y de las Juntas Rectoras en la gestión del Espacio Natural (Parque Natural más Parque Nacional, Doñana y Sierra Nevada), sobre unos sesenta miembros solo tres representantes de las Federaciones Andaluzas antes mencionadas.

A todas luces, un número insuficiente en cuanto al potencial de usuarios que las actividades deportivas en el medio natural aportan, por lo que sería conveniente una mayor presencia de los diferentes segmentos de los agentes deportivos en estos órganos, esto es: deportistas, técnicos, clubes, federaciones de todas las modalidades que se practican en el ENP, empresas de turismo deportivo, centros escolares, etc., donde su labor coadyuvaría con la Administración a una mejor ordenación, conservación, gestión y uso público de los recursos naturales.

Todo ello, implementaría la participación de los ciudadanos y usuarios para el cumplimiento efectivo que, establece la Ley 5/2016, en cuanto a la normativa que regule la ordenación en materia de medio ambiente tendrá en cuenta el uso deportivo (art.10.4); luego, una medida de gran calado sería modificar la estructuras de las Juntas Rectoras de los Parques Naturales y los Consejos de Participación de los Parques Nacionales, dándoles el protagonismo que requieren los operadores deportivos que, insistimos, pueden ser un elemento muy valioso a la hora de colaborar con la Administración en la protección y conservación de los ENP.

Así las cosas, estas reformas estructurales posibilitarían la colaboración interadministrativa que tanto se echa de menos en la actualidad, la cual se hace visible 
cuando la nueva Ley establece que las consejerías competentes en materia de deporte, turismo y medio ambiente, promoverán la colaboración para la práctica del deporte en el medio natural como elemento generador de actividad turística (art.10.6).

\section{EL FOMENTO DE LA PRÁCTICA DEL DEPORTE EN EL MEDIO NATURAL COMO DESARROLLO SOSTENIBLE}

La clásica distinción que hace años hiciera Jornada de Pozas, en materia de intervencionismo administrativo - policía, fomento y servicio público- que, en virtud del principio de intercambiabilidad de las técnicas de intervención en la actividad deportiva se puede apreciar en las mismas, es la actividad de fomento, tal y como recoge el artículo 43.3 de la $\mathrm{CE}^{11}$ la más utilizada para estimular, impulsar, favorecer, ayudar, etc., la actividad deportiva.

Entre los medios de fomento utilizados, se encuentra con gran relevancia los instrumentos normativos, con los que podemos decir que constituyen la percha de la cual se cuelgan las posteriores acciones, tal y como lo entiende la Ley 5/2016 cuando, a diferencia de su antecesora, se pronuncia sin ambages por que los poderes públicos fomentarán la práctica del deporte en el medio natural de una manera sostenible con el medio ambiente, de acuerdo con la normativa aplicable en materia de medio ambiente (art.10.1), facilitando esta actividad mediante programas específicos en la planificación tanto de actividades como de eventos (art.10.2).

Por tanto, son dos las subdivisiones que se desprende del contenido de los apartados del artículo; el fomento de la actividad deportiva en el medio natural y su compromiso con el desarrollo sostenible, planteamientos éstos que, perfectamente son asumibles, tanto por las federaciones deportivas como por los propios clubes.

\section{El impulso del deporte en el medio natural a través de títulos habilitantes, además de la licencia deportiva. Una vis expansiva para fortalecer las estructuras deportivas}

Si tomamos la exposición de motivos de la Ley 5/2016 podemos encontrarnos como una de las justificaciones de la ley, está basada en el dinamismo continuo que presenta el sector deportivo, por lo que exige adecuar su regulación a las nuevas demandas que plantea la ciudadanía andaluza en el siglo XXI (ap .III).

$11 \mathrm{Al}$ respecto ya en su día, se puso de manifiesto por un lado el juego constitucional que daría el artículo 43.3 de la CE, así como, por otro lado, el resto de artículos que incidirían en la actividad deportiva. BERMEJO VERA, J., "Constitución y Ordenamiento Deportivo", en Revista Española de Derecho Administrativo, núm. 63 (1989), pp. 337 y ss.; y BERMEJO VERA, J., Constitución y Deporte, Tecnos, Madrid, 1999. 
Consideración ésta, que ya llevaba años planteándose en numerosos foros, sobre todo a principios de la década del 2000, cuando a través del Instituto Andaluz de Deporte (IAD), se celebraron numerosos seminarios gracias al coraje y tesón del entonces Secretario General Técnico de la Consejería de Turismo y Deporte Rafael Rodríguez de León, sobre "estructuras federativas", "deporte y medio ambiente", etc., donde la conclusión siempre llegaba al mismo sitio: "hay numerosos practicantes de deportes que no están en el marco de la ley 6/1998"o, lo que es lo mismo decir que, en algunas modalidades deportivas, son más los practicantes no federados que los federados -ciclismo, BTT, montaña, atletismo, esquí, etc.,-, por lo que a estos deportistas deberían de ir las siguientes reformas legislativas, debido a que una ley, como la ya derogada, estaba pensada exclusivamente en el marco del deporte federado y de competición, llevando a la obsolescencia a una norma de espaldas a la realidad, contraria a los vientos que no hacen avanzar la embarcación.

Ahora, la nueva Ley, extiende sus brazos y da cobertura a toda práctica deportiva, sin distinción de la finalidad con que la hace el deportista, atendiendo a velar porque todos los deportistas estén acogidas a su amparo para, poder de esta forma, convertir en aplicables unos principios rectores (art.5) que, de no materializarse, se convertirían en mera retórica jurídica literaria como tantas veces sucede.

Por ello, la mejor medida de fomento que puede hacer la Administración deportiva es favorecer el fortalecimiento del tejido asociativo, impulsando a través de programas el que las federaciones deportivas andaluzas procedan a expedir el título habilitante, distinto a la licencia deportiva, ya que ésta se reserva para participar en las competiciones deportivas oficiales (art.25.1); y, de esta forma, se de paso a la tarjeta federativa para aquellos deportistas que desean estar vinculados con su práctica de ocio y de no competición oficial a una federación deportiva.

Eso sucedería, principalmente, en todas aquellas modalidades y especialidades que se desenvuelven en el medio natural, donde tantas veces vemos a miles de ciudadanos que salen al campo, la montaña, a los ríos, los embalses, las carreteras comarcales, etc., que no están federados porque sencillamente su actividad es meramente placentera o de recreo, y la licencia deportiva no les reporta nada más que costos y escasos beneficios.

En resumidas cuentas, lo que hace la Ley es abrir a las federaciones deportivas una vis expansiva, para que fortalezcan su tejido asociativo incrementado por el número de deportistas que, con este título habilitante, se incorporarían a las estructuras del deporte federado, eso sí, respetando la singularidad propia del deporte de ocio, que, nunca, puede ser obstáculo para los fines clásicos del deporte federado.

Y en lo que respecta a las actividades de control de la Administración en los ENP, qué duda cabe que cuantos más practicantes, en definitiva usuarios del espacio 
natural, estén integrados en una federación, perfectamente identificados y comprometidos con los valores ambientalistas, van a constituir un elemento colaborador de indudable valor, sobre todo, porque se erradicaría uno de los elementos favorecedores del mal trato ambiental, como es la clandestinidad y el anonimato de los agresores del medio ambiente.

Estos planteamientos, en la nueva Ley, son perfectamente asumibles por dos razones: la primera, porque las federaciones deportivas pueden expedir estos títulos para participar en competiciones no oficiales y de ocio, eso sí, siempre que lo prevean los estatutos (art.25.4), por lo que la Administración deportiva debe de favorecer con las medidas oportunas -subvenciones- a las federaciones, para que incluyan estas actividades en sus estatutos; y la segunda, para hacer efectivos toda la pléyade de derechos del deportista que se contemplan, entre éstos disponer de los mecanismos para la protección de la salud, el desarrollo de la actividad competicional en condiciones de seguridad, contar con medidas que favorezcan la práctica del deporte de ocio (art. 36), que igualmente tienen su acomodo al prever la norma que, en las competiciones no oficiales y deporte de ocio, la organización - puede ser perfectamente el club- garantizara los medios de protección sanitaria de participantes que den cobertura a los riesgos que derivados de la práctica (art.42.3).

Así las cosas, a sensu contrario, si el seguro obligatorio de accidentes en las competiciones oficiales está integrado en la licencia deportiva, siendo gestionado el seguro por la propia federación (art42.1), no hay impedimento alguno a que las federaciones andaluzas expidan un título habilitante, que puede ser la "tarjeta federativa", u otro nombre, y se les exija a los club que aporten para su expedición la cobertura sanitaria, es decir el seguro, en los términos que se determine reglamentariamente, que perfectamente puede ser gestionado por cada club según sus propias características e intereses.

\section{El compromiso con el desarrollo sostenible}

Si el deporte como cualquier actividad humana se desarrolla en un espacio físico concreto de un territorio, esto supone: por un lado, la idoneidad del lugar para la realización de acciones determinadas; y, por otro, la posibilidad de deteriorar el medio ambiente por la presencia del hombre, es lógico que la Administración deportiva se comprometa con el desarrollo sostenible, tal y como lo define el Informe Brundtlant de 1987: "aquel desarrollo que satisface las necesidades del presente, sin comprometer las capacidades de las futuras generaciones para satisfacer sus propias necesidades".

$\mathrm{Al}$ respecto son numerosos los instrumentos normativos que se pronuncian en materia de deporte y sostenibilidad, por lo que la Ley 5/2016, no hace más que alinearse como no podía ser de otra forma, con el discurrir de los tiempos, donde 
vamos a dar, a título de ejemplo, unas breves pinceladas que nos permitan apreciar, al menos panorámicamente, estos compromisos.

Es el caso de la Carta Europea del Deporte de 1992 y revisada en 2001, en la que nos encontramos en su apartado 9, el siguiente texto: "teniendo presente la estrecha relación existente entre medio ambiente sano y las actividades deportivas, y considerando la necesidad de atender los datos de medio ambiente y al principio de desarrollo sostenible", recomienda a los gobiernos que, en sus políticas nacionales en materia de deporte, se basen en los principios de la Carta, donde en el artículo 10 está dedicado al deporte y a los principios de desarrollo sostenible, para que se adopten medidas destinadas a apoyar los esfuerzos de las organizaciones deportivas dirigidas a la conservación de la naturaleza y el medio ambiente.

Otro buen ejemplo nos lo ofrece El libro blanco sobre el Deporte de la Comisión Europea, de 11 de julio de 2007, donde se incluye entre sus objetivos (apartado 2.8) el desarrollo sostenible, en cuanto la práctica del deporte, así como las instalaciones y acontecimientos deportivos tienen un impacto significativo en el medio ambiente, por lo que es importante promover la gestión sana del entorno, debiendo las organizaciones deportivas europeas y los organizadores de acontecimientos deportivos establecer objetivos medioambientales para que sus actividades sean sostenibles con el medio ambiente.

Por último, a nivel internacional, la Carta Olímpica, texto vigente de julio de 2011, al hablar del Movimiento Olímpico y su actividad, regula entre las funciones del COI las de estimular y apoyar una actitud responsable en los problemas del medio ambiente y promover el concepto de desarrollo sostenible del medio ambiente (art. 2.13).

Y ya dentro de nuestro país, destacamos el Código de Buen Gobierno de la Federación Española de Deportes de Montaña y Escalada, que hace referencia a través de la participación responsable y a la práctica del deporte, a la sensibilidad en materia de sostenibilidad de respeto al medio ambiente.

En definitiva, la práctica del deporte ha contado, como no podía ser de otra forma, con numerosos instrumentos proteccionistas, de los que las modalidades especialidades deportivas principalmente relacionadas con el mismo, han tenido siempre como referente. Es el caso, las numerosas actividades que realizan a lo largo del año con prácticas de sensibilización en cursos y actividades ecológicas, que van desde la limpieza de cauces de ríos a la recuperación de senderos y caminos; por tanto, la mejor medida de fomento por parte de las Administraciones sería el reconocimiento de estas funciones facilitando los usos de determinados espacios protegidos, así por ejemplo la licencia deportiva o la tarjeta federativa sería el título habilitante para 
acceder a las prácticas de ciertos deportes en zonas prohibidas. Nadie mejor que los deportistas para velar por el desarrollo sostenible del lugar.

\section{LA GESTIÓN DE LOS ESPACIOS NATURALES PROTEGIDOS (ENP) ANTE LAS ACTIVIDADES DEPORTIVAS Y EN ESPEGIAL LOS INSTRUMENTOS DE ORDENAGIÓN}

Merece especial atención cuando hablamos de actividades deportivas en la naturaleza, como objeto de este estudio, aquéllas que se realizan en espacios naturales protegidos, por ser en éstos lugares físicos donde se aprecia con mayor intensidad la intervención pública a través de los instrumentos de ordenación o regulación; esto es, aquéllos que establecen con carácter general los límites y condiciones del ejercicio de actividades privadas sujetas a algún tipo de intervención administrativa, de los instrumentos o técnicas de control, lo que se traduce en el ámbito de este tipo de actividades a estar limitadas por medio de vigilancia, inspección, prohibiciones, autorizaciones, limitaciones y sanciones en función de las correspondientes normativas de utilización, y, sobre todo, de los planes respectivos, que irrumpen con notable intensidad para regular las relaciones entre el hombre y su hábitat ${ }^{12}$.

Sin soslayar que existen otro tipo de intervenciones públicas, muy amplias, menos restrictivas, destinadas al disfrute del espacio natural en las mejore condiciones posible, como sucede con las acciones de carácter económico (recursos humanos, infraestructuras,) de fomento y educación ambiental, de seguridad y prevención, etc.; en este trabajo, nos vamos a centrar en algunas de ellas de carácter jurídico, que encuentran en numerosas ocasiones el rechazo de los usuarios-deportistas, al no poder desarrollar su actividad en el ENP, debido a las diferentes normativas, a los instrumentos de planificación y al escaso apoyo que encuentran en los órganos de participación.

Todo ello nos conduce a una Intervención pública, control, que se realiza en: delimitaciones, autorizaciones, limitaciones, prohibiciones, sanciones, etc., que propician un malestar de los usuarios, al ver como los instrumentos prohibitivos, se imponen a la ordenación y regulación de la actividad, como decíamos anteriormente, por citar un ejemplo, con la bicicleta de montaña, escalada, actividades aeronáuticas, descensos de ríos, espeleología, etc.

Descartando aquellas actividades que se realizan en bienes de naturaleza privada, como pueden ser montes privados, zonas de acampada particulares, lagunas de fincas propias, etc., así como de dominio público de uso común general que se

12 SAnCHEZ MORÓn, M., Derecho Administrativo. Parte General, Tecnos, Madrid, 2018, pp.661-696. 
ejerce libremente por los usuarios de forma acorde con la naturaleza de los bienes ${ }^{13}$ : caminos, paseos, parques, estanques, puentes, vías pecuarias clasificadas, etc. Aunque, efectivamente, en estos bienes públicos se desarrollan actividades deportivas, nos encontramos con normativas de uso, como horarios, limitaciones, etc., que son de regulaciones menos intensas, que las que se producen en los espacios naturales protegidos, aunque muchas veces pasen desapercibidas al usuario practicante deportivo.

Hablar, por tanto, de gestión, es referirnos a quien tiene la competencia de gestionarlo $^{14}$, la normativa sobre espacios naturales es, pues, fundamentalmente de origen autonómico, por lo que hay que atender así a la legislación de cada Comunidad Autónoma, para conocer las categorías de espacios y su régimen específico.

Por lo tanto, la primera actuación de intervención pública en materia ambiental serán las de carácter jurídico, a través de los diferentes instrumentos normativos (leyes y reglamentos) principalmente de signo autonómico ${ }^{15}$, por las que se ejercen las competencias respectivas en materia ambiental.

Igualmente, debemos de tener muy en consideración que, dentro de los medios jurídicos, se encuentra la Planificación como técnica de protección ambiental, cuya principal función es garantizar la utilización racional del territorio o de los recursos naturales, pero de forma más concreta, es una técnica muy eficaz para concretar y especificar las medidas de prevención o restauración, previstas con carácter abstracto por la legislación ${ }^{16}$.

Podemos destacar por su incidencia, en las actividades deportivas, los Planes de Ordenación de Recursos Naturales (PORN) cuyo objeto es el establecimiento y la definición de objetivos, acciones y criterios que promuevan la conservación, el uso sostenible; y, en su caso, la restauración del patrimonio, recursos naturales terrestres y marinos, y de la biodiversidad y de la geodiversidad; y Los Planes Rectores de Uso y Gestión (PRUG) que son los que fijan las normas generales de uso y gestión de los

13 RIVERO YSERN, J,L., Manual de Derecho Local, 6a edición, Civitas, Madrid, 2010.

14 Véase ESTEVE PARDO, J., Derecho del Medio Ambiente, Marcial Pons, Madrid, 2008, ya ponía el acento en el papel fundamental de las Comunidades Autónomas.

15 Véase LÓPEZ MENUDO, F., "concepto de medio ambiente y reparto competencial", en D. VERA JURADO (director), Derecho Ambiental de Andalucía, Tecnos, Madrid, 2005, pp. 31-46; LÓPEZ RAMÓN, F., Política ecológica y pluralismo territorial. Ensayo sobre los problemas de articulación de los poderes públicos para la conservación de la biodiversidad, Marcial Pons, Madrid, 2009.

16 CONDE ANTEQUERA, J., "Instrumentos públicos de protección ambiental II: el control administrativo de la implantación y puesta en funcionamiento de las actividades con incidencia ambiental", en M.A. TORRES LÓPEZ y E. ARANA GARCÍA (directores) Derecho Ambiental Adaptado al EEES, Tecnos, Madrid, 2018, pp.92-103. 
Parques, conteniendo el régimen al que quedan sometidos los usos y actividades que se desarrollen en el Parque o espacio natural protegido.

Una participación efectiva de las federaciones deportivas en los instrumentos de planificación, fortalecería la interacción usuarios-medio natural-Administración, por lo mucho que pueden aportar estos usuarios, a los que vamos a llamar cualificados, por su intensa relación permanente, no esporádica, con el medio natural, al ser los primeros interesados en conservar y proteger el medio ambiente, constituyendo una opinión relevante sobre las actividades a realizar, no por supuesto vinculante, pero si altamente cualificada, sobre todo por el alto grado de tecnificación que están adquiriendo las modalidades y especialidades en el deporte en la naturaleza.

Ante estos planteamientos, aumentar la presencia de los operadores deportivos en los órganos de los ENP, como venimos manteniendo nos parece muy importante, pues como acabamos de exponer son numerosos los instrumentos de intervención pública de los que disponen las Administraciones, principalmente autonómica, para ejercer sus competencias en materia ambiental.

Destacamos, lógicamente por orden de importancia, determinadas medidas jurídicas concretas, entre las que se encuentran por su incidencia la regulación de la composición, régimen jurídico y funciones de las Juntas Rectoras de los Parques Naturales, a las que nos referíamos antes, frente a la escasa representación de operadores deportivos, en este caso de Andalucía.

Órganos colegiados de participación de la Consejería de Medio Ambiente, en los términos previstos en el artículo 20 de la Ley 2/1989, de 18 de julio por la que se aprueba el Inventario de los Espacios Naturales de Andalucía (artículo que fue modificado por la Ley 6/1996, de 18 de julio) que, entre sus importantes funciones, tiene la de informar el Plan de Ordenación de los Recursos Naturales (PORN). Asimismo, estas Juntas Rectoras aprueban provisionalmente el Plan Rector de Uso y Gestión (PRUG) donde se pormenorizan las directrices del PORN, artículo 13 de la Ley 2/1989, contemplando con minuciosidad las prescripciones que debe seguir la Administración competente a la hora de gestionar el parque.

En el caso particular de Andalucía, debemos de desatacar el Decreto 239/1997, de 15 de octubre, por el que se regula la constitución, composición y funciones de las Juntas Rectoras de los Parques Naturales, para ello fija en el anexo la composición de los miembros que componen cada uno de estos órganos, es en este apartado donde podemos ver, con unos ejemplos, el repetido escaso protagonismo que tienen los agentes deportivos, cuando, al menos, en algunas zonas de los parques que constituyen el mayor número de usuarios. 
Así las cosas, teniendo en cuenta que los números son aproximados, pues pueden depender del total de municipios afectados, de las asociaciones de vecinos, Diputaciones, etc.; pues bien, podemos decir que en, términos generales número arriba y número abajo, a título de ejemplo: en el Parque Natural de la Breña y Marismas del Bárbate de 37 miembros más los representantes de los municipios, tan sólo 3 son representantes de Federaciones Andaluzas de Deportes, que se corresponderán en todos los parques con los deportes más practicados en el parque natural, debiendo ser uno de éstos el representante de la Federación Andaluza de Caza; Parque Natural de los Alcornocales, de 50 miembros, 3 representantes de FDA; Parque Natural de Hornachuelos de 37 miembros, más los representantes de ayuntamientos, tan sólo 3 representantes a propuestas de las FDA; Parque Natural de la Sierra de Huétor, de 34 miembros más los representantes de ayuntamientos, un total de 2 representantes de la Federación Andaluza de Caza y uno de Montañismo..., etc., por lo tanto la conclusión, no puede ser más desalentadora, sólo se contemplan tres representantes de las Federaciones Deportivas Andaluzas, según las características del parque, si bien predomina la de Caza, en la composición de las Juntas Rectoras de los Parques Naturales de Andalucía.

Igualmente, de frustración, podemos ver en los dos emblemáticos Parques Nacionales de Andalucía: Doñana y Sierra Nevada, a los que el Decreto 24/2007, de 30 de enero, por el que se declara el Espacio Natural de Sierra Nevada y se regulan los órganos de gestión y participación de los Espacios Naturales de Doñana y Sierra Nevada.

Para analizar esta norma, hay que partir de la Ley 8/1999, de 27 de octubre, del Espacio Natural de Doñana, que define como figura de protección ambiental el Espacio Natural de Doñana, en el que quedan englobados los territorios tanto del Parque Nacional como del Natural, siendo ambos sometidos a una gestión unitaria, que como se pronunció el Tribunal Constitucional en la ST 331/2005, de 15 de enero, la citada Ley no vulnera la competencia del Estado.

Por otro lado, el Real Decreto 712/2006, de 9 de junio, por el que se amplían las funciones y servicios de la Administración del Estado a la Comunidad Autónoma de Andalucía en materia de conservación de la naturaleza, el Estado traspasó a Andalucía las funciones y servicios referidos a la administración y gestión de los Parques Nacionales de Doñana y Sierra Nevada, que han sido asignados a la Consejería de Medio Ambiente en virtud del Decreto 137/2006, de 4 de julio.

Atendiendo a los argumentos expuestos anteriormente, el presente Decreto, con el fin de garantizar la gestión integral del Parque Nacional y del Parque Natural de Sierra Nevada, traslada al mismo el modelo de gestión establecido en la Ley 8/1999 del Espacio Natural de Doñana, que creó el Consejo de Participación que asume las 
funciones que corresponden a los Patronatos de los Parques Nacionales y a las Juntas Rectoras de los Parques afectados.

Este Consejo de Participación, se define en el artículo 7.1, como: "un órgano de colaboración y coparticipación entre las Administraciones implicadas donde se ha de hacer efectiva la coordinación interadministrativa exigida constitucionalmente y además servir a la necesaria intervención de los ciudadanos en la gestión del Espacio Natural...", correspondiéndole entre sus funciones las de informar de todos aquellos planes que afecten a la ordenación y gestión de los recursos naturales, así como de las actuaciones actividades relacionadas con su conservación y uso público, entre otras.

Es en el anexo del Decreto, donde encontramos la composición de ambos Consejos de Participación: así en el del Parque Nacional de Doñana, de aproximadamente unos sesenta miembros, tan sólo un representante de las Federaciones Deportivas, en este caso, de Caza; y en el Parque Nacional de Sierra Nevada, también sobre sesenta miembros, tres representantes de las Federaciones Andaluzas de Caza, Pesca y Montaña.

A todas luces, un número insuficiente en cuanto insistimos el potencial de usuarios deportivos que las actividades en la naturaleza aportan en estos Espacios, donde, como decíamos, una mayor presencia de los diferentes segmentos de los agentes deportivos: empresas de turismo deportivo, deportistas, técnicos, clubes, federaciones en todas las modalidades que se puedan realizar (Montaña, Espeleología, BTT, Piragüismo, Deportes Aéreos, Hípica, Deportes de Invierno, etc.,), centros escolares, etc., facilitarían una mejor ordenación de la actividades deportivas con la preservación del medio ambiente, por lo que desde estas líneas reiteramos el aumento de la presencia de los operadores deportivos en los órganos de participación de los ENP.

\section{LAS FEDERAGIONES DEPORTIVAS COMO AGENTES COLA- BORADORES DE LA ADMINISTRACIÓN EN MATERIA DE MEDIO AMBIENTE Y SEGURIDAD EN LA PRÁCTICA DEL DE- PORTE EN EL MEDIO NATURAL}

Sorprendentemente hasta la entrada en vigor de la Ley 10/90, de 15 de octubre, del Deporte, la naturaleza jurídica de las Federaciones Deportivas en España, era un enigma jurídico, pues no existía precepto alguno que la definiera al respecto, bien como ente privado o bien como ente público, de esta problemática la doctrina ha dado buena cuenta ${ }^{17}$; pero fue la propia Ley estatal, quien despejo la incógnita

17 ESTEVE PARDO, J., "Las asociaciones deportivas de configuración legal. El caso de las Federaciones Deportivas", en Revista Española de Derecho Administrativo, núm. 45, (1985), pp. 113 y ss; FUERTES LÓPEZ, M., Asociaciones y Sociedades Deportivas, Marcial Pons, Madrid, 1992; BERMEJO VERA, J., "La 
al sentar en su articulado (art. 30.1 y 30.2) recogiendo la doctrina del Tribunal Supremo ( ST de 19 de julio de 1984), con motivo de la impugnación del Real Decreto 643/1984, de 28 de marzo, sobre estructuras federativas; por violación del artículo 22 de la Constitución, presentada por la Federación Española de Judo y Disciplinas Asociadas, al establecer que las funciones públicas de la Federaciones Deportivas Españolas no violentan el derecho de asociación reconocido en la Constitución, al igual que la doctrina del Tribunal Constitucional de 24 de mayo de 1985, que considera que las Federaciones Deportivas Españolas son asociaciones de configuración legal.

En definitiva, las Federaciones Deportivas Españolas son asociaciones de configuración legal, que se constituyen de acuerdo con su legislación sectorial, de naturaleza privada y ejercen funciones públicas de carácter delegado, actuando en este caso, como agentes colaboradores de la Administración, por lo que cuando actúan en el ejercicio de estas funciones, sus actos serán recurribles ante la Administración deportiva. Por ejemplo, las sanciones deportivas impuestas por los órganos disciplinarios de una Federación Deportiva Española pueden ser recurridas ante la Administración del Estado, es decir ante el Tribunal Administrativo del Deporte órgano independiente del Consejo Superior de Deportes, similares planteamientos a nivel autonómico, en estos casos, ante la Administración en materia de deportes en cada Comunidad Autónoma.

Por lo tanto, las federaciones deportivas, tanto estatales como autonómicas, son polimórficas, en cuanto unas veces actúan como entes privados según sus estatutos y otras como entes agentes colaboradores de la Administración, bajo los criterios y tutela de ésta, siendo estas funciones donde vamos a centrar nuestra propuesta.

Si nos detenemos en estas funciones públicas delegadas podemos encontrar en su listado las siguientes: calificar y organizar, en su caso, las actividades y competiciones oficiales; expedir las licencias deportivas, coordinar y controlar las ayudas públicas; colaborar en las formaciones deportiva conducentes a las titulaciones oficiales; ejercer la potestad disciplinaria; ejecutar las resoluciones de los órganos administrativos en materia de disciplina deportiva, etc.

Sin embargo, no vamos a encontrar ninguna función pública relacionada con la actividad deportiva en el medio natural, de ahí que vamos a proponer su inclusión, siempre y cuando lo permita su ubicación jurídica entre las citadas competencias delegadas, como vemos en el caso concreto de la Ley 5/2016, de 19 de julio, del Deporte de Andalucía, al establecer en su artículo 60.2 las funciones que las Federaciones Deportivas Andaluzas que pueden ejercer bajo los criterios y tutela de la Consejería

dimensión constitucional del Derecho de Asociación”, Revista de Administración Pública, núm.136, (1995), pp.119 y ss.; AGUIRREAZKUENAGA ZIGORRAGA, I., Intervención Pública en el Deporte, IVAP-CIVITAS, Madrid, 1998. 
competente en materia de deporte, en su apartado 2.g): "cualquier otra que reglamentariamente se determine".

Por lo que en este caso, bastaría por incorporar en vía reglamentaria al Decreto por el que se regulen las Federaciones Deportivas Andaluzas en desarrollo de la nueva Ley, una función pública delegada en materia de: "protección y conservación del medio ambiente a través de las actividades deportivas, y seguridad en la práctica del deporte en el medio natural"'. Función que, se articularía atendiendo a la figura del Convenio entre las Consejerías competentes en materia de Deporte y de Medio ambiente, con las Federaciones Deportivas Andaluzas, o con las respectivas en otras Comunidades Autónomas, -art. 47 y ss., de la Ley 40/2015, de 1 de octubre, de Régimen Jurídico del Sector Público-, habida cuenta que las Comunidades Autónomas, independientemente de la legislación básica sobre protección de medio ambiente que le corresponde al Estado, tienen facultades para establecer normas adicionales de protección. En el sentido que establece el artículo 149.1.23 a a título general; y, ya en concreto la gestión de los Espacios Naturales Protegidos, las cual recae en manos de las Administraciones Autonómicas, como sienta la jurisprudencia, entre sus pronunciamientos, STC 102/1995, de 25 de junio y STC 194/2004, de 10 de Noviembre,

Esta es la forma jurídica, creemos más adecuada, de dar respuesta al artículo 4 de la Ley 5/2016, cuando preceptúa que la normativa que regule la ordenación del medio ambiente tendrá en cuenta la práctica deportiva; de la misma forma que, el artículo 6 mandata a las Consejerías competentes en materia de deporte, turismo y medio ambiente la colaboración para la práctica del deporte en el medio natural, incluyendo, desde nuestro punto de vista, una desafortunada mención al elemento generador de actividad turística.

Lo afirmamos, pues este elemento ya está implícito en el deporte en el medio natural para quien se traslada a un lugar distinto al de su residencia, esto es el turista deportivo, luego no hace falta su inclusión, pues supone dar relieve a la actividad turística, cuando el factor sustantivo es la actividad deportiva, sea uno turista o practicante del entorno, a ello ya nos hemos referido en otros trabajos.

Por lo tanto, nada mejor para poder cumplir con la Ley andaluza, tanto en la práctica deportiva en el medio natural a nivel general, como cuando ésta se desarrolla en los sitios de máxima protección en los ENP, que contar con las Federaciones Deportivas Andaluzas, lo que supone también adecuar la gestión de estos espacios a la propia Ley 33/2015, de 21 de septiembre, por la que se modifica la Ley 42/2007, de 13 de diciembre, del Patrimonio Natural y de la Biodiversidad, que apuesta por la participación de la ciudadanía en el diseño y ejecución de las políticas públicas dirigidas a la consecución de los objetivos de la ley (art.2. h), decimos que es una apuesta, pues la modificación legal incluye un nuevo apartado (k) destinado a los habitantes 
y propietarios de terrenos, con lo que se viene a reforzar no sólo el papel de los ciudadanos, sino que se de esta forma se incrementan las prácticas de buen gobierno.

Con este acomodo legal, no tenemos duda en afirmar que las federaciones deportivas constituyen un elemento vertebrador muy importante como asociaciones sin ánimo de lucro, para encauzar la participación de los ciudadanos, máxime cuando al estar integradas en las Federaciones Españolas la propia ley las declara de utilidad pública (art. 53 Ley 5/2016).

\section{EL GASO GONGRETO DE LOS SENDEROS DE USO DEPORTIVO EN ANDALUCÍA: EL DEGRETO 67/2018, DE 20 DE MARZO}

\section{Del trampantojo legal de la norma a una colaboración intensa entre Administración y Federaciones deportivas}

Prueba evidente de nuestros planteamientos, en cuanto a la viabilidad de las federaciones deportivas como agentes colaboradores de la Administración en materia de protección de medio ambiente y seguridad en la práctica del deporte en el medio natural, en virtud del ejercicio de funciones públicas delegadas ${ }^{18}$, es el Decreto $67 / 2018$, de 20 de marzo, por el que se regulan los senderos de uso deportivo en la Comunidad Autónoma de Andalucía, que desarrolla la Ley 3/2017, de 2 de mayo, de regulación de los senderos de la Comunidad Autónoma de Andalucía.

Ley a la que podemos tildar de "instrumento legal trampantojado", por cuanto el propio título de la norma cotejado con el contenido, produce una ilusión, en este caso jurídica, igual al que podemos apreciar en aquellos paisajes pintados que simulan una imagen real, que no se corresponde con la realidad, pues se trata de una muy exigua ley que no aporta, en sus escasos 5 artículos y 2 disposiciones finales, prácticamente nada, pues como dice su artículo $1^{\circ}$, a la hora de determinar el objeto de la ley, se trata de :"establecer el marco regulador a partir del cual se van a desarrollar las diferentes funciones sociales, económicas, culturales, educativas y deportivas de los senderos de Andalucía", dejando absolutamente todo el contenido sustantivo a la potestad reglamentaria de las Administración competente en materia de medio ambiente, ordenación del territorio, deporte y turismo, luego la pregunta es obvia ¿Para ese viaje no hacen falta alforjas?.

Si bien, no es el momento para abordar la gestación de este trampantojo legal, por cuanto a la relevancia política con la que sus gestores la presentaban, si queremos

18 Tal y como expusimos en nuestra intervención en el CIMAS 2018, CONGRESO INTERNACIONAL DE LAS MONTAÑAS, Granada 8-10 de marzo de 2018, JIMENEZ SOTO, I., "El control administrativo de las actividades deportivas en los Espacios Naturales Protegidos. A propósito de la viabilidad de colaboración de las Federaciones Deportivas, Libro de Actas del Congreso, pp. 589-603. 
indicar, al menos, la frustración plena, de quienes esperaban en ella un instrumento, para de una vez establecer las obligaciones de construcción, mantenimiento, protección de la señalización, régimen sancionador propio, utilización de propiedad privada en senderos de uso público, dotaciones presupuestarias, etc., que no encontramos en la ley.

Ello no obsta a que, pese al ridículo contenido de la norma legal, no es menos cierto que, en su desarrollo, ha propiciado una norma reglamentaria que, si bien no soluciona en parte los problemas importantes que tiene el senderismo, a algunos de los cuales nos referiremos en este trabajo, permite disponer de un reglamento que tiene en su haber:

A) Gracias a la conjunción del artículo 10.3 de la Ley 5/2016, de 19 de julio, del Deporte de Andalucía, con el del artículo 4.b de la Ley 3/2017, el de considerar al sendero de uso deportivo, como una instalación deportiva no convencional, con lo que se refuerza el papel que tienen los senderos en la actividad deportiva, en los operadores deportivos, coadyuvando con el protagonismo que el sector deportivo debe de tener en los espacios naturales donde se práctica deporte.

Consecuencia de ello, se crea una nueva Sección en el Inventario Andaluz de Instalaciones y Equipamientos, con la denominación de Red de Senderos de Uso Deportivo de Andalucía (modificando el Decreto 284/2000, de 6 de junio por el que se regula el Inventario Andaluz de Instalaciones Deportivas), Registro por tanto de carácter administrativo, cuyos efectos serán declarativos y no constitutivos, por cuanto como deja caer el artículo 17,en relación a los efectos y obligaciones de la declaración, que emite la Secretaría General para el Deporte, en esta declaración: " 1. La resolución supondrá otorgar a un sendero la condición de uso deportivo, no alterando, dicha circunstancia, en ningún caso, la titularidad pública o privada de los terrenos que lo integren. El uso de dichos senderos será gratuito".

Es decir, el reconocimiento de un sendero como de uso deportivo, solamente afectará a aquellos senderos que, a través de un promotor de forma voluntaria (artículos 11 y 12), bien sea persona física o entidad pública o privada, decida iniciar el procedimiento para el reconocimiento de un sendero con esta denominación, siendo quien asume todos los costes derivados del mismo, debiendo de obtener el consentimiento de todas las personas titulares de los terrenos por los que vaya a discurrir el sendero. Lo peor para el promotor, debe de asumir la garantía de la financiación de los costes asociados al trámite de homologación, la señalización y el mantenimiento del sendero y de su adecuación.

Así pues ¿en estas condiciones quien va a asumir el papel del promotor de un sendero de uso deportivo?, la respuesta será muy fácil al ver el número de senderos 
que finalmente se van a inscribir como senderos de uso deportivo, con lo que se podrá comprobar la bonanza de la norma reglamentaria, por el contrario, su desatino.

B) Sin lugar a dudas, el acierto de la norma es cuando el artículo 6, describe las funciones públicas delegadas, utilizando para ello el anclaje al que nos referíamos, por nuestra parte en páginas anteriores en nuestra aportación al Congreso Internacional de las Montañas (CIMAS 2018) y lo hace de la siguiente forma: "1. De conformidad con el artículo 60.2.g) de la Ley 5/2016, de 19 de julio, a los efectos exclusivos de lo previsto en el presente Decreto, se delega en la Federación Andaluza de Montañismo la competencia pública de homologación de senderos en su condición de agente colaborador de la Administración en el desarrollo y promoción del senderismo". Igualmente, esta delegación de funciones públicas se extiende a aquellas modalidades y especialidades deportivas distintas al senderismo, pero que discurran por senderos, como sería el caso de la Federación Hípica para senderos ecuestres, o la actividad de bicicleta de montaña (entre las federaciones de ciclismo y montaña).

A tal efecto, en el ejercicio de esta función pública delegada les corresponde: a) la evacuación de un informe de viabilidad que tendrá carácter vinculante, obsérvese la intensidad de la norma, que se aparta de los criterios normales que tiene la Administración en materia de informes en cualquier procedimiento administrativo, donde prima el de carácter preceptivo y no vinculante, pues aquí no; es decir, el ente privado a través de su decisión vincula a la propia Administración, en este caso, a la Secretaría General del Deporte, que es quien instruye y resuelve el procedimiento (art. 10.2); y b) la emisión de un certificado de homologación a fin de confirmar el cumplimiento de los requisitos de señalización y adecuación del sendero.

Sin duda, como acabamos de exponer, se trata del ejercicio de una función pública delegada por la Administración a una entidad privada, una federación deportiva, de forma intensa, pues al reconocer la especialidad que la Federación Andaluza de Montañismo, tiene en cuanto a su vinculación a los senderos, porque así lo tiene reconocido en sus estatutos, fuentes terciarias, o de otras federaciones a las que afecte la bicicleta de montaña o la práctica deportiva a caballo, está publificando una actividad deportiva como es la homologación de senderos. Por cierto, tradicional, que cuenta con una gran bagaje normativo al estar registradas sus señales, a favor de la Federación Española de Deportes de Montaña y Escalada, en el Registro Oficial de Marcas y Patentes (GR, PR y SL) en cuanto a Gran recorrido, Pequeño recorrido y Sendero Local.

Consecuencia de todo ello es que, la actividad delegada al estar publificada, entra en la órbita de la tutela administrativa que ejerce la Administración correspondiente, en este caso, la Secretaría General del Deporte, quien no solamente instruye y resuelve los procedimientos, sino que será la competente para resolver las contro- 
versias, vía de recurso administrativo, en la tramitación del procedimiento, e incluso en la revocación de la declaración (art.22).

La asignación normativa al ente federativo de estas funciones públicas delegadas, no es una materia propia y exclusiva, en lo que afecta a los senderos de Andalucía, pues son numerosas las Comunidades Autónomas que han otorgado, con más o menos intensidad, a sus respectivas federaciones deportivas ${ }^{19}$.

Es más, esta función de agentes colaboradores de la Administración en materia de protección de medio ambiente, pues no debemos de olvidar que el sendero se convierte en un instrumento vital al permitir el acercamiento del ser humano al medio natural, incluso con la calificación de "recurso turístico", se ve enormemente potenciada con la homogeneización en la "terminología en los Espacios Naturales Protegidos", fruto de la colaboración entre la Federación Española de Deportes de Montaña y Escalada y el Organismo Autónomo Parques Nacionales ${ }^{20}$, consecuencia de los documentos elaborados en Jaca 2003 y Valsain 2017.

\section{Naturaleza jurídica del suelo de los senderos}

Con el símil de trampantojo al que hacíamos referencia en líneas anteriores, queremos incidir, en la enorme frustración con la que fue recibida la Ley, por parte

19 Por citar a algunas de ellas, Véase el Decreto 79/1996, de 16 de abril, de Ordenación y Normalización de Senderismo en el País Vasco; Decreto 59/1998, de 9 de octubre de Ordenación del Senderismo en el Principado de Asturias; Decreto 179/2004, de 24 de septiembre, de regulación del senderismo y deportes de montaña de forma compatible con la conservación del medio natural; Decreto 11/2005, de 15 de febrero, por el que se crea la Red Canaria de Senderos y se regulan las condiciones para la ordenación, homologación y conservación de los senderos; Decreto Foral núm. 197/2011, de 7 de septiembre, que regula las condiciones para la creación y conservación de los senderos deportivos de uso público de la Comunidad Foral de Navarra; Decreto 159/2012, de 19 de junio, que regula los senderos de Aragón que revisten las condiciones de recursos turísticos, en este Decreto la señalización se remite al Manual de Senderos Turísticos de Aragón aprobado por Orden de 4 de noviembre de 2013. En todas estas normas se reconoce la función de homologación realizadas por las federaciones de montañismo que tienen registradas GR y PR que conectan con las redes europeas ya implantadas.

20 Véase Terminología sobre Deportes de Montaña en la Normativa de Espacios Naturales Protegidos, FEDME, 2018, en este interesante documento podemos encontrar las definiciones de: abrigo de montaña; acampar; acampada nocturna; albergue de montaña; baño; barranquismo; barranquismo en cauce acuático; barranquismo en cauce seco; carrera por montaña; coastering; correr por montaña; deportes de montaña; escalada clásica; escalada deportiva; escalada en bloque; escalada en hielo; escalada mixta; escalada en vías ferratas; esquí de montaña; guía de montaña benévolo; guía de montaña profesional; marcha nórdica; mojón o hito de montaña; monitor de montaña; montañismo; pernocta; progresión en terreno abrupto; raquetas de nieve; refugios de montaña; refugio guardado o refugio de montaña guardado; refugio-vivac; sector de escalada; senderismo; senderos homologados; senderos señalizados; snowboard de montaña; travesía de montaña (trekking); vadear; vía ferrata; vicac/vivaquear y zona de escalada. Y todo ello para facilitar la elaboración e interpretación de los Planes de Ordenación de Recursos Natrales (PORN) y Planes Rectores de Uso y Gestión (PRUG). 
de numerosos colectivos de quienes, entre los que se encuentra este autor, esperaban mucho más de una norma.

Sobre todo, debía de hacer referencia a una de las cuestiones más importantes que nos suceden a quienes practicamos el senderismo, la marcha, la carrera de montaña, la bicicleta de montaña, etc., o simplemente necesitamos desplazarnos a un lugar determinado a través de un sendero, donde en un momento determinado, se encuentra con una propiedad privada, que simplemente te prohíbe el paso ${ }^{21}$. Pues el sendero que discurre por zona pública, por ejemplo un camino o vía pecuaria, se encuentra en un lugar de su recorrido con una cerrado metálico, valla, puerta, etc., que simplemente te impide el paso.

La Ley 3/2017, (art.2) define el sendero: "todo itinerario que transcurre en la mayor parte de su recorrido por el medio natural, recorriendo un patrimonio natural y cultural a través de caminos tradicionales, veredas, pistas forestales u otras vías del territorio en Andalucia, y que está habilitado para la marcha, excursionismo, fundamentalmente a pie, y a veces en bicicleta o caballería".

A continuación (art.4) se distinguen los siguientes usos principales de los senderos: a) Medioambiental; b) Deportivo; c) Turístico, encontrándonos la siguiente definición del deportivo: "son senderos de uso deportivo aquellos que sean señalizados, homologados y autorizados atendiendo al procedimiento que se regule mediante decreto, a los efectos de la práctica deportiva y, por tanto, se constituyan en una instalación deportiva no convencional, de conformidad con lo establecido en el artículo 4.ñ. $2^{a}$ de la Ley 5/2016, de 19 de julio, del Deporte de Andalucía”.

Así las cosas, no solamente en la Ley de senderos de Andalucía, sino también en los numerosos decretos al efecto, ya mencionados, no vamos a encontrarnos referencia alguna a la naturaleza jurídica sobre la propiedad de los senderos ${ }^{22}$, por la sencilla razón que es una materia con numerosas aristas, con repercusiones importantes que tiene, no sólo a efectos de libertad de tránsito, sino también de responsabilidades, sobre todo para el propietario del espacio físico donde se asienta el sendero.

Si bien, cuando éste en su totalidad es de naturaleza pública, no suele plantear problemas "de tránsito o paso", o incluso de responsabilidades en materia de conservación o de responsabilidad patrimonial, pues el acervo normativo es importante, cuyo punto de partida lo tenemos en el artículo 132 de la CE donde dice: "la ley regulará el régimen jurídico de los bienes de dominio público y de los comunales, inspirándose en los

21 A tal efecto el IV Seminario Internacional sobre Senderismo y Territorio en Europa: “Derecho deportivo: uso abierto y propiedad privada"; Málaga, 2008, Europeans Ramblers Association y Federación Española de Deportes de Montaña y Escalada, nos encargó una ponencia al respecto publicada en el libro de Actas de la Diputación Provincial de Málaga organizadora del Evento, pero lo importante es la temática del Seminario propiciado por la Asociación más importante de senderismo de Europa.

22 A esta cuestión ya refiere NASARRE SARMIENTO, J M. (2016: 38-75). 
principios de inalienabilidad, imprescriptibilidad e inembargabilidad, así como su desafectación", aunque mucho antes, ya en 1889, el propio Código Civil, se refiere a ellos en el artículo 339 al definir los bienes de dominio público:" los destinados al uso público, como los caminos, canales, ríos, torrentes, puertos y puentes construidos por el Estado, las riberas, las "playas, radas y otros análogos"; concretando, más adelante, en el artículo 344 que, entre los bienes de uso público, en las provincias y los pueblos, se encuentran los caminos provinciales y los vecinales, por lo que éstos tienen la consideración jurídica de bienes demaniales destinados al uso público ${ }^{23}$.

Por tanto no hay duda alguna que, cuando el sendero discurre por un camino público, o por una vía pecuaria (cuya Ley 3/1995, de 23 de marzo le otorga la categoría de bienes de dominio público), la conservación, su uso, disfrute, etc., será de carácter público; si bien, no es de extrañar que, en el ámbito local, nos encontremos con alguna ordenanza municipal o provincial que contenga disposiciones en materia de conservación, mantenimiento, uso, horarios, etc., consecuencia de la propiedad del sendero público, que, como indica NASARRE SARMIENTO ${ }^{24}$, esta circunstancia resulta extrema, puesto que frecuentemente se plantea la duda sobre quién pesa la responsabilidad en la conservación de caminos, cuando por ellos transcurren itinerarios que han sido señalados, y tal vez acondicionados por diferentes instituciones u organizaciones.

En definitiva, como es el propietario del terreno por donde discurre el sendero el responsable de la conservación de los caminos y vías rurales, los daños que se produzcan como consecuencia de su mal estado, conservación, funcionamiento, etc., estarán dentro del instituto de la responsabilidad patrimonial (Estado, Comunidad Autónoma, Entidad local), regulado en los artículos 32 a 37 de la Ley 40/2015, de 1 de octubre, de Régimen Jurídico del Sector Público, y en la especialidades procedimentales de la Ley 39/2015, de 1 de octubre, del Procedimiento Administrativo Común, (artículos 65 ,67, 81, 91, entre otros).

No obstante, creemos conveniente resaltar, por la naturaleza del espacio físico por donde transcurre el sendero, que los particulares tienen derecho a ser indemnizados por las Administraciones Públicas correspondientes, de toda lesión que sufran, en

$23 \mathrm{Y}$, como tales, son acogidos en la propia legislación de régimen local, esto es, a partir de la Ley 7/1985, de 2 de abril, Reguladora de las Bases de Régimen Local y su posterior Texto Refundido del RD Legislativo 781/1986, en cuyo artículo 74 señala como bienes de uso público local los caminos, carreteras, puentes... cuyo aprovechamiento, conservación y policía son de las entidades locales; al igual que el Real Decreto 1372/1986, de 13 de junio, por el que se aprueba el Reglamento de Bienes de las Entidades Locales, así como la Ley 33/2003, de 3 de noviembre, del Patrimonio de las Administraciones Públicas, donde en los artículos 4-6 encontramos los bienes y derechos de dominio público, por lo que se encuentran afectados al uso general o al servicio público.

24 NASARRE SARMIENTO, J.M., (2016: 55). 
este caso por funcionamiento normal o anormal del sendero público, esta misma responsabilidad exonera a la Administración, cuando se trata de casos de fuerza mayor (art. 32.1 Ley 39/2015), la cual tiene su origen fuera del ámbito del funcionamiento del servicio público, entre las que se destacan las causa naturales, como pueden ser tormentas, terremotos, deslizamientos, etc., en definitiva acciones causadas por hechos irresistibles, insuperables, imprevistos, no así por los casos fortuitos en los que si responde la Administración ${ }^{25}$, al estar dentro del ámbito de su funcionamiento.

Obviamente, si los daños se ocasionan en un sendero de naturaleza privada, una finca particular, por ejemplo, entrará en juego el instituto de la responsabilidad civil consecuencias de las obligaciones que nacen de la culpa o negligencia del Código Civil (1902 y ss.).

Así las cosas, como podemos apreciar, la propiedad del suelo por donde transcurre el sendero es muy importante, pero todavía no hemos respondido a qué sucede ¿Cuándo el sendero público se corta al llegar a una finca privada? Que, como advertimos, no soluciona ni la Ley 3/2017 de senderos, ni el Decreto 67/2018 por el que se regula su uso.

Para ello, vamos a estudiar las soluciones que se pueden ofrecer, comenzando por la que podríamos tildar de "amistosa", que ya la ofrece el artículo 12.2) del Decreto, cuando en la solicitud de declaración de los senderos de uso público que presente el promotor, debe de ir, entre otra documentación: c) "el consentimiento de todas las personas titulares de los terrenos por los que vaya a discurrir el sendero, a cuyo efecto se aportarán los documentos que en Derecho permitan acreditar de forma fehaciente dicha circunstancia”.

Por más vueltas que queramos darle, el documento que acredite la circunstancia, en este caso, de paso por la finca privada, es el "Convenio" que el promotor, privado, o público, que será el más lógico, es decir un ayuntamiento, diputación provincial, una mancomunidad, etc., firme con el titular de la propiedad; en el caso de ser una entidad pública, su régimen sería el establecido en los artículos 47 a 53 de la Ley 40/2015, como acuerdos entre Administraciones Públicas con sujetos de Derecho privado para un fin común, en este caso, el tránsito por la finca privada, más el contenido específico que las partes quieran añadir como la señalización, el mantenimiento, la adecuación, etc. Sin olvidar todas aquellas cláusulas que afecten a compensaciones económicas, si las hay, disponibilidad de uso, etc.; nuevamente, si el acuerdo o convenio es entre particulares, su régimen será el establecido en Derecho Civil, como sería el caso de una empresa turística promotora de un sendero de uso deportivo.

25 TORRES LÓPEZ, M.A., "La responsabilidad patrimonial de la Administración Pública”, en Conceptos para el estudio del Derecho Administrativo en el Grado", Tecnos, Cuarta edición, Madrid, 2017, p.128. 
No obstante, podría darse el caso, no infrecuente que, el titular de la finca, por tratarse de un uso inveterado que se remonta a años, hasta el momento no ofrezca impedimento alguno al tránsito de montañeros, senderistas, ciclistas, jinetes a caballo, etc.; es decir, una costumbre arraigada en la zona, para lo que no pone objeción alguna, es una situación de hecho, de precario, que no ofrece problema alguno al dejar las cosas como están; entre éstas, el limbo de las responsabilidades, en caso de que se exijan, en las que el propietario lo tiene muy claro al decir que esa parte del sendero es privada, y no entra en el dominio de sus responsabilidad los que entran en ella sin su autorización o consentimiento.

Sin embargo, ahora cuando se puede reconocer el espacio de propiedad privada como integrante de un "sendero de uso deportivo", la situación puede cambiar sensiblemente, porque si el desfiladero, la cascada, la vía de acceso a la montaña, el embalse, etc., privado, por el que transcurre un sendero homologado y autorizado, e inscrito en un Registro Público, como es la Red de Senderos de Uso Deportivo en Andalucía, en caso de producirse algún accidente, la cadena de responsabilidades se activará en diversas direcciones: promotor, titular del sendero, Junta de Andalucía a la que pertenece el Registro, etc., por lo que el propietario de la parte privada del sendero, querrá en el convenio que autorice el paso por su finca, tener cubiertas sus espaldas, exigiendo que se pacten las condiciones en materia de responsabilidad.

Por lo que paradoja del destino, el sendero de toda la vida, por el que el propietario de la finca privada no ponía objeción a que se pudiera transitar por su finca, ahora al convertirlo en "sendero de uso deportivo", puede poner todas las trabas del mundo a que nadie atraviese su finca por motivos de responsabilidad civil que, si no se soluciona con el convenio, asistiríamos a un efecto perverso de la norma, como es el cierre, la valla, el candado en la puerta, que ahora impide el paso por la propiedad.

Estas situaciones que se pueden presentar, es lo que nos anima a utilizar la fórmula de la "expropiación forzosa"26 , cuya definición nos la ofrece BERMEJO

26 La figura de la expropiación forzosa consta de gran predicamento en la doctrina administrativista como se puede aprecia, entre otros en: BERMEJO VERA, J., (otros), "Expropiación Forzosa", número monográfico, Documentación Administrativa, núm. 222. 1991; LÓPEZ MENUDO, F., CARRILLO DONAIRE, J, A., GUICHOT REINA, E., La expropiación forzosa, Lex Nova, Valladolid, 2006; BARCELONA LLOP, J., "Privación de la propiedad y expropiación forzosa en el Sistema del Convenio Europeo de Derechos Humanos", Revista de Administración Pública, 2011, núm. 185; DESDENTADO DAROCA, E., La expropiación de los enclaves privados del litoral, Civitas, Madrid, 2007; FUERTES LÓPEZ, M., y BOIX PALOP, A., Problemas actuales de la expropiación forzosa (volumen colectivo de la Asociación Española de Profesores de Derecho Administrativo), Instituto Nacional de Administración Pública, Madrid, 2012; SOSA WAGNER,F., (coordinador), Comentario a la Ley de Expropiación Forzosa, Aranzadi, 200;UTRILLA.FERNÁNDEZ BERMEJO, D., Expropiación forzosa y beneficiario privado: una reconstrucción sistemática, Marcial Pons, Madrid, 2015. OLMEDO GAYA, A., "La expropiación forzosa", en M. TORRES LÓPEZ, (coord.) en Conceptos para el estudio del Derecho Administrativo II en el Grado, Tecnos, quinta edición, Madrid, 2017, pp.143-166. 
VERA $^{27}$ como una compraventa impuesta obligatoriamente por la exclusiva voluntad del comprador -o adquiriente- al dueño o titular de la cosa o titular del derecho, involuntario vendedor. Pero este tipo de compraventa forzosa, en la que el comprador ejerce una prerrogativa tan importante, solo pueda llevarla a cabo algunos poderes públicos, cuando es necesario para los intereses generales y, desde luego, pagando su precio.

Instituto, éste el de la expropiación forzosa, que constituye por su clamorosa ausencia, el gran fallo de la trampantojada Ley 3/2017, de senderos de Andalucía, ante la no declaración de "utilidad pública" o "interés social" de los senderos en las diferentes modalidades de medio ambientales, turísticos y deportivos. Por lo que se ha perdido una excelente oportunidad de, independientemente de la tipología del sendero, cuando éste se encuentre con una propiedad privada que impide el tránsito, se pueda aplicar de forma sencilla la expropiación forzosa, convirtiendo el sendero en todo su recorrido en bien demanial.

Ahora bien, como fórmula jurídica exorbitante, lo que la convierte en un instrumento excepcional por cuanto quiebra con el derecho constitucional de la propiedad (art. 33.1 CE), el ejercicio de esta potestad se encuentra limitado por la normas, tal y como lo entiende el propio texto constitucional: "nadie podrá ser privado de sus bienes y derechos, sino por causa justificada de utilidad pública o interés social, mediante la correspondiente indemnización y de conformidad con lo dispuesto por las leyes".

Por lo tanto, como toda potestad administrativa, la expropiación forzosa está sujeta al principio de legalidad, que, en este caso, ya viene de años anteriores a la actual Constitución del 78, pues su marco vigente arranca de la Ley de 16 de diciembre de 1954, de Expropiación Forzosa, (LEF) y su Reglamento de 26 de abril de 1957 (REF), si bien se ha ido actualizando algunas materias de la LEF por los Estatutos de Autonomía y otras leyes como LBRL ${ }^{28}$, por cuanto el sujeto expropiante está reser-

27 Bermejo VERA, J., Derecho Administrativo Básico Parte Especial, Volumen II, Civitas Thomson Reuters, Cizur Menor, 2017, p. 261.

28 Por cuanto el artículo 4.1 d) de la Ley 7/1985, de 2 de abril Reguladora de las Bases de Régimen Local (LRBRL), enumera entre las potestades de los Municipios, Provincias e Islas, la potestad expropiatoria, y en el artículo 4.2 establece que lo dispuesto en el número precede: "podrá ser de aplicación a las Entidades Territoriales inferior al Municipio y, asimismo, a las Comarcas, Áreas Metropolitanas y demás Entidades Locales, debiendo las leyes de las Comunidades Autónomas cual de aquellas potestades serán de aplicación"; No obstante, conviene recordar que las Entidades de ámbito territorial inferior al municipio ,denominadas también entidades locales menores (caseríos, parroquias, aldeas, barrios, anteiglesias, consejos, pedanías, anejos y otros análogos), se han visto sensiblemente modificadas por la Ley 27/2013, de 27 de diciembre, de racionalización y sostenibilidad de la Administración Local (LRSAL), que suprime estas entidades locales menores, en la nueva redacción de la planta local del $\operatorname{art}^{\circ} 3.2$., si bien se permite la subsistencia de las ya existentes siempre que saneen sus cuentas. Por otra parte, las leyes de las Comunidades Autónomas podrán crear estas entidades, pero sin personalidad jurídica (art. 24. Bis LRBRL), por lo que 
vado a las Administraciones Públicas: Estado, Comunidades Autónomas, Provincias y Municipios, (art. 2.1 LEF) quedando excluidos por tanto los entes que integran la Administración Institucional (STS 25 de octubre de 1982).

Para proceder a la expropiación forzosa es necesario la existencia de la causa expropiandi, esto es la previa declaración de "utilidad pública" o "interés social" (art. 9LEF); es decir, el motivo que justifica el ejercicio de dicha potestad a favor de la Administración, si bien no son figuras algunas veces fáciles de distinguir, nosotros nos quedamos con la "utilidad pública" que se reconoce respecto a obras y servicios de titularidad pública (vías de comunicación y transportes, ferrocarriles, presas, embalses, depósitos de residuos, etc.), no cabe duda que los senderos de uso deportivo, son vías de comunicación, por tanto puede ser declarados de utilidad pública a efectos de expropiación forzosa, cuando se corta un vial público por atravesar una finca privada a la que se dueño se opone al tránsito.

Esta declaración de utilidad pública o interés social, que legitiman la expropiación de inmuebles, requieren normas con rango legal, como se desprende del explícito planteamiento del texto constitucional (art. 53.3), por lo que solo pueden ser configuradas tales declaraciones por los poderes legislativos, lo que nos lleva a la necesidad de determinar ¿si debe de ser por ley Estatal o bastaría tan sólo ley de la Comunidad Autónoma?

Ello nos conduce a un breve análisis de la legislación aplicable al respecto, donde partiendo, como no podía ser de otra forma del texto constitucional, el artículo 149.1. 18 ${ }^{\mathrm{a}}$, reserva al Estado la competencia legislativa sobre expropiación forzosa y no sólo de las bases de esta materia, lo que significa, según reiterada doctrina del STC 37/1987, STC 61/1997,STC 164/2001; STC 14/2007, que corresponde al Estado regular en exclusiva la expropiación en su faceta o dimensión de garantía de los derechos e intereses económicos privados, y en consecuencia, los criterios y sistema de valoración del justiprecio, así como el procedimiento expropiatorio, para impedir: " que los bienes objeto de expropiación puedan ser valorados con criterios diferentes en una y otras partes del territorio nacional y que se prive a cualquier ciudadano de alguna de las garantías que comporta el procedimiento expropiatorio", pero esta exclusividad no impide, como dice SÁNCHEZ MORÓN ${ }^{29}$ que tanto el Estado como las Comunidades Autónomas, en

continúan careciendo de potestad expropiatoria; por tanto, en casi todas las leyes de las CGAA nos vamos a encontrar que la potestad expropiatoria la tienen atribuida a las áreas metropolitanas, las comarcas y mancomunidades. Véase JIMÉNEZ SOTO, I y CASTILLO RAMOS-BOSSINI, S, "Otras Entidades locales para la prestación de servicios y el ejercicio del gobierno en el territorio", en Lecciones para el estudio del Derecho Local en el Grado, Coordinador F. CASTILLO BLANCO en, Tecnos, segunda edición, Madrid, 2019, pp.139-168.

29 SÁnCHEZ MORÓn, M., Derecho Administrativo. Parte General, decimocuarta edición, Tecnos, Madrid, 2018, p.758. 
el ámbito de sus respectivas competencias materiales, puedan regular la expropiación forzosa en su faceta de potestad pública o instrumento del que sirven para el logro de sus fines; en definitiva, supone que corresponde a uno y otras la determinación legal de la causa expropiandi en materias o sectores de su competencia, que es lo que la Ley 3/2017 de Andalucía tenía que haber incluido en su articulado.

En este mismo sentido, se pronuncia BERMEJO VERA ${ }^{30}$, para quien una interpretación estricta del artículo 149.1.18 a , nos llevaría a la conclusión de que este imprescindible instrumento de acción pública quedaría fuera del alcance de la Comunidades Autónomas y de las Entidades Locales, porque si solamente el Estado tiene potestad para legislar sobre expropiación forzosa y sus causas de utilidad pública o interés social, las CG.AA y mucho más las Administraciones locales se encontrarían desapoderadas para expropiar, lo cual es inasumible.

Así las cosas, seguirá argumentado el profesor, parece fuera de duda que la voluntad de los constituyentes fue, en materia de expropiación forzosa, habilitar al legislador estatal para establecer condiciones uniformes para la privación forzosa del derecho de propiedad, distinguiendo con claridad entre lo que representa promulgar una legislación y lo que implica utilizar las técnicas e instrumentos regulados en ella, tal y como lo expresa rotundamente el Tribunal Constitucional (STG 17/1990): "la reserva constitucional a favor del Estado sobre la legislación de expropiación forzosa no excluye que por Ley autonómica puedan establecerse en el ámbito de sus propias competencias, los casos o supuestos en que procede aplicar la expropiación forzosa, determinando las causas de expropiar o los fines de interés público a que aquélla ha de servir. De lo contrario se llegaría al absurdo de que las Comunidades Autónomas, habiendo constatado la existencia de nuevas causas de utilidad pública o interés social justificadoras de la expropiación para el desarrollo de sus competencias, tuvieran que solicitar del Estado la regulación formal de aquellas".

Por lo tanto, partiendo del marco que establece la actual Ley de Expropiación Forzosa, como garantía de los derechos e intereses económicos privados, las causas expropiandi pueden ser determinadas en leyes estatales o autonómicas, dentro de sus competencias, por lo que teniendo la Comunidad Autónoma de Andalucía competencias exclusivas en "Medio Ambiente, espacios protegidos y sostenibilidad" (art. 57); "Turismo" (art. 71) y "Deportes, espectáculos y actividades recreativas" (art. 72), según el Estatuto de Autonomía de Andalucía, LO 2/2007, de 19 de marzo, no existe impedimento competencial alguno, a que el Parlamento andaluz en la Ley 3/2017, hubiera declarado de" utilidad pública" los senderos como parte de la infraestructura viaria; es decir, declaración genérica y directa de utilidad pública a través de una ley sectorial, técnica muy utilizada en determinados sectores: artículo 103 de la Ley 34/1998, de 7 de octubre, del sector de Hidrocarburos; artículo 54 de la Ley 24/2013, de 26 de

30 BERMEJO VERA, J, (2018:275-276). 
diciembre, del Sector eléctrico; o ya en este ámbito el ambiguo artículo 4.2 de la Ley 42/2007, de 13 de diciembre, del Patrimonio Natural y de la Biodiversidad que dispone:" Las actividades encaminadas a la consecución de los fines de esta ley podrán ser declaradas de utilidad pública o interés social, a todos los efectos y en particular a los expropiatorios".

Más concretamente, en la Ley 1/2019, de 30 de enero de la Actividad física y el deporte de Canarias, cuyo artículo 47 se convierte en un magnífico ejemplo, destinado a la "Declaración de utilidad pública", contiene el siguiente tenor: "La aprobación de los planes autonómicos, insulares y municipales de instalaciones deportivas, implicarán la declaración de utilidad pública de las obras incluidas en los mismos, a efectos de expropiación forzosa o imposición de servidumbres legales, sobre los terrenos y edificios precisos para su ejecución".

Si la Ley hubiera declarado de forma genérica la causa expropiandi para los senderos, bastaría después solamente realizar " el Acuerdo de necesidad de ocupación", que consiste en un acto administrativo por parte de la Administración expropiante donde se determinan: cuáles son los bienes a expropiar, la extensión necesaria, la condición de expropiados, posible sustitución de los bienes elegidos, etc., concretándose esta fase con una información pública y el preceptivo trámite de audiencia a los interesados (artículos 15 a 23 LEF), para continuar con las demás fases del procedimiento expropiatorio.

Lógicamente al no haber recogido expresamente la Ley 3/2017, la causa de expropiación, para los senderos de uso deportivo al pasar su recorrido por una finca privada, es muy complicada, pues falta la cobertura legal necesaria que establece la Constitución; por su propia naturaleza, se descartan las leyes expropiatorias singulares, las cuales al no permitir el recurso en vía administrativa deben de ser excepcionales y proporcionales (STC 48/2015, de 3 de marzo).

Sin embargo, no todo está perdido, pues la legislación expropiatoria básica, esto es la LEF (art. 10), entiende implícita la utilidad pública "en todos los planes de obras y servicios del Estado, Provincia y Municipio", por lo que bastaría que, por ejemplo un ayuntamiento o una diputación provincial, en la aprobación de sus respectivos planes de obras y servicios, como son los de naturaleza deportiva, esto es piscinas, polideportivos cubiertos, campos de fútbol, etc., se incluyan determinados senderos, con lo cual se lleva aneja la declaración de utilidad pública para los fines expropiatorios. Pero, no obstante, insistimos, aunque sea para visualizar su importancia, le ley sectorial debía de haber incluido su utilidad pública.

$\mathrm{Al}$ respecto, es conveniente recordar que los caminos y vías rurales forman parte de la infraestructura viaria, que es una competencia propia en los términos de la LBRL (con las modificaciones de la LRSAL, establecida en el artículo 25.2.d); competencia que está incluida en los Planes Provinciales de Cooperación a la Obras y Servicios de competencia municipal (art. 36.2.a), los cuales se subvencionan con los 
medios propios de la Diputación o entidad equivalentes, los municipios, la Comunidad y el Estado, por lo que no hay inconveniente alguno que, desde la misma manera, que se construye un polideportivo municipal con fondos de las diferentes Administraciones (se excluye la del Estado salvo que sea de interés nacional para el alto nivel deportivo), los senderos puedan formar parte de estos Planes, que, nuevamente, se echa de menos en el trampantojo legal, el cual debería de haber contado con unas partidas presupuestarías al efecto, criterios de priorización, condiciones técnicas, etc.

\section{LA PRÁCTICA DEPORTIVA DEL ESQUÍ Y SUS ESPECIALIDA- DES A TRAVÉS DE LICENGIA O TÍTULOS HABILITANTES}

Obviamente, las modalidades y especialidades deportivas del esquí, están perfectamente inmersas, en nuestra propuesta de "protección y conservación del medio ambiente y seguridad en la práctica del deporte en el medio natural". Sin embargo, además de esta función, esta última parte del trabajo, se centra en la respuesta a la siguiente pregunta ¿es necesario algún requisito para la práctica del esquí?, o por el contrario ¿es suficiente como hasta ahora pagar el forfait como único requisito?, la respuesta como veremos no es fácil.

Sobre todo porque somos conscientes que es una materia de difícil calado por dos motivos: el primero, porque no debemos de olvidar que las estaciones de esquí y montaña son sociedades mercantiles de capital privado o mixto, cuya sostenibilidad financiera reside en los ingresos que recauda, por lo que establecer requisitos para su práctica podría ser un freno a los usuarios, con la consiguiente merma en los ingresos; y el segundo, desde la visión del practicante deportivo, cualquier requisito podría también entenderse como una traba más al ejercicio de una actividad de ocio, dirigiendo sus preferencias de ocio a otras actividades que no requieren requisito alguno.

Aun así, con estos interrogantes lo cierto es que una de las cuestiones que más preocupa a los responsables de las Estaciones de Esquí y Montaña, es la seguridad de la práctica deportiva de los esquiadores, pero no solamente aquella que es consustancial a la misma actividad, ampliamente cubierta con los correspondientes seguros de daños- incluido el transporte por cable- y responsabilidad civil principalmente de la estación, sino aquella que se produce como consecuencia de las conductas de determinados esquiadores, al provocar accidentes por malas prácticas, estado de embriaguez, drogas, etc.; es lo que algunos profesionales del esquí denominan "la cultura del botellón en las pistas", no obedeciendo las señales e indicaciones, no respetando las instrucciones de los empleados, descendiendo de forma provocativa para impactar con otros esquiadores para producir lesiones considerables, utilizando de forma inapropiada los medios mecánicos, etc.; es decir, conductas que traen "por la calle 
de la amargura a los gestores de las Estaciones", todo ello, por la falta de cobertura jurídica que tienen las fuerzas y cuerpos de seguridad para poder intervenir en la práctica del esquí, simplemente por la ausencia de normativa específica al respeto ${ }^{31}$, lo que les impide actuar ante el máximo cumplimiento del principio de legalidad, por cuya virtud la potestad sancionadora de las Administraciones Publicas, se ejercerá cuando haya sido expresamente reconocida por una norma con rango de ley (art. 25 de la LRJSP).

Por supuesto, no nos estamos refiriendo a las empresas que gestionan las estaciones de esquí y montaña, que no tienen capacidad sancionadora, a lo sumo se le podría aplicar la Ley 13/1999, de 15 de diciembre, de Espectáculos Públicos y Actividades Recreativas, con un entramado normativo disperso como el Decreto 10/2003, de 28 de enero, de Reglamento General de Admisión en los Establecimiento de Espectáculos Públicos, junto al Decreto 155/2018, de 31 de julio, por el que se aprueba el Catálogo de Espectáculos Públicos y Actividades Recreativas, donde no incluye a las estaciones de esquí y montaña, luego habría que incluirlas en la categoría de la disposición adicional $9^{\mathrm{a}}$, 13, de complejos deportivos.

Todo para poder a través del servicio de seguridad privada, tras una reglamentación propia, a lo sumo expulsar al "perturbador" de la estación, pero muy difícil el poder aplicar un régimen sancionador que correría a cargo de la Administración competente de estas materias, Gobernación y Justicia, o su correspondiente en cada legislatura, pensando principalmente para los empresarios y organizadores de eventos.

Lo importante no es solamente poder actuar sobre el "perturbador", sino que su actuación lleve implícita una sanción, bien económica o de suspensión temporal para la práctica deportiva del esquí; en definitiva, sería aplicar un mecanismo muy similar al del Código de Circulación ¿sería posible?

Esta problemática no es de ahora, pues ya en 2006 el Senado español aprobó el Informe de la Ponencia ${ }^{32}$ "para el estudio del fenómeno de la desestacionalización en el sector turístico y para la elaboración de una propuesta normativa que garantice el uso racional de las estaciones de esquí" (543/000007), llegando en sus conclusiones, a través de la formulación de propuestas y recomendaciones, entre otras: "6.1. Que se adopte por el Gobierno, junto con las Comunidades Autónomas y, en su caso, con los Ayuntamientos afectados, una iniciativa normativa con rango de Ley en la que se establezca y regule con carácter

31 A todo ello, ya nos referíamos en JIMÉNEZ SOTO, I. (2015:243-295).

32 Comisión de Industria, Comercio y Turismo (Diario de Sesiones, Comisiones, núm.272, de 23 de febrero de 2006, en toda su amplitud Véase Informe de la Ponencia de estudio sobre el uso racional de las estaciones de esquí, Secretaría General del Senado, Dirección de Estudios y Documentación, Departamento de Publicaciones, Madrid, 2006. 
general el régimen jurídico que garantice y fomente el uso racional de las estaciones de esquí, definiéndose a los centros o estaciones de deportes de nieve y de montaña y las condiciones que éstas deben reunir, así como las obligaciones de sus gestores y los deberes de los usuarios".

Sin embargo, la realidad es que han ido pasando los años, aumentando el número de usuarios y practicantes deportivos en las estaciones de esquí y montaña, sin que haya iniciativa legislativa alguna al respecto, sustituyendo esta orfandad jurídica en un Reglamento de Funcionamiento de las Estaciones de Esquí Españolas integradas en la Asociación Turística de Estaciones de Esquí y Montaña (ATUDEM), fundada en 1974 en la que se agrupan 35 estaciones existentes en España que fue elaborado en 1994, experimentando sucesivas actualizaciones, la última de la Asamblea celebrada en Madrid en 2017, incorporando las Normas de Conducta de la Federación Internacional de Esquí (FIS) para esquiadores y snowboarders de julio de 2002.

Se trata como hemos mantenido en otros trabajos, de una norma de carácter convencional, nacida de la buena voluntad de sus miembros, que no es otra que un exponente del consenso de las estaciones de esquí para paliar la situación de inseguridad jurídica en la que se desenvuelve su gestión. Por ello, la fuerza coercitiva de la misma es muy escasa, en lo que se refiere a su aplicación a terceros, al ser ésta una norma convencional libremente pactada por los que suscriben el reglamento, lo que difícilmente se puede aplicar a aquellos que no lo han suscrito como son los usuarios; aunque ello no es obstáculo a que estas normas sirvan de interpretación por los Tribunales de Justicia en materia de accidentes de esquíi3 pero que, en modo alguno, supone habilitación legal para que puedan intervenir las fuerzas del orden público (Guardia Civil, Policía Nacional Adscrita a la Comunidad Autónoma y Policía Local) para quienes violen las reglas de la práctica del esquí.

Podemos decir que es verdaderamente sorprendente que una actividad la que se crea en las Estaciones de Esquí y Montaña, según ATUDEM; que genera 100.000 puestos directos e indirectos, con un impacto económico estimado en los $750 \mathrm{mi}$ llones de euros, no cuente con un ordenamiento jurídico sectorial, quizás debido a las fuertes contradicciones que surgen en torno al ámbito competencial estatal o autonómico, al contenido de la materia deportiva, turística y como no ambiental, al conglomerado de propietarios de las diferentes estaciones, etc., en resumidas cuentas, sean las razones que sean, a día de hoy la demanda de los gestores de las estaciones de esquí y montaña, porque se regule normativamente la práctica y seguridad de los deportes del esquí y sus especialidades, no ha encontrado respuesta de los poderes pú-

33 Por ejemplo, Sentencia de la Audiencia Provincial de Granada, Sección $3^{\text {a }}$, de 16 de febrero de 1999 (AC1999/3827), o la Sentencia del Juzgado Mixto número 1 de Puebla de Trives de 5 de octubre de 2000, en las que se tiene en cuenta que las pistas estaban balizadas con arreglo a la reglamentación de las pistas. 
blicos, luego la pregunta es obvia y a su respuesta va dedicada esta parte del trabajo, anudando a las otras interrogantes ¿qué se puede hacer al respecto?

Lo suyo, sin lugar a dudas, sería contar con una ley específica como sucede con la Ley Italiana de 24 de diciembre de $2003^{34}$, norma en materia de seguridad en la práctica de deportes invernales de descenso y de fondo, cuya gestación fue posible gracias a una reforma de la Constitución en 2001, en materia de competencias entre el Estado y las Regiones; en este caso, se trataba de una materia que ya había sido regulada por las regiones, pero ${ }^{35}$ insuficiente para solucionar la problemática que se estaba generando, por lo que era necesario una intervención estatal dirigida a establecer unas normas de carácter general, que califiquen los remontes y las áreas destinadas al esquí, todo ello provocado por las alarmas sociales ante la seguridad y siniestralidad de la montaña.

En definitiva, entre sus normas de comportamiento, se encuentran en los artículos 9 a 15, algunas de las recomendaciones de conductas dictadas por la FIS, mundialmente conocidas y aceptadas, como hemos visto en el Reglamento de ATUDEM, ahora elevadas a rango legal, lo que permite intervenir para su control, vigilancia y socorro a las fuerzas y cuerpos de seguridad italianos (Policía del Estado, Cuerpo Forestal del Estado, el Arma de Carabinieri y la Policía Local).

Sin embargo, por la razones antes expuestas, el modelo italiano se encuentra a años luz del español, nos consta que desde ATUDEM siguen realizando gestiones al respecto, pero mientras tanto habría que dar respuestas, y una de ellas la vamos a encontrar en lo que ya planteábamos en 2015, esto es: la viabilidad de incardinar la práctica del esquí y sus especialidades en la Administración deportiva a través de la licencia deportiva, ampliamente reforzada por el reconocimiento legal del deporte de ocio, de la competición deportiva no oficial, y sobre todo por la aparición en el ámbito autonómico de "los títulos habilitantes" que, en definitiva, pueden ser la llave que abra la puerta.

Veamos pues, las Federaciones Deportivas, como sabemos, realizan dos tipos de funciones; las propias, y las delegadas de carácter administrativo; entre las primeras, se encuentra la promoción y desarrollo de las modalidades y especialidades

$34 \mathrm{Al}$ respecto Véase CHIEPPA, R, y DELLANTONIO, M., "La nouva legge sullo sci: regole di comportamiento e responsabiltá nelle aree sciabili lo sci alpino, lo sci fuoropista e le competenze nell' attivittá di prevenzione valanghe”, en Diritto e formazzione,núm. 2 (2005), p. 178; BRUCCOLERI, C., "Ordinamento sciitistico italiano", en I Forumn Jurídico Europeo de la nieve, "Dai diritti della neveal Diritto della neve", en Professione de Montagna, núm. 85 (2006).

35 Trentino-Alto Adile (1970); Veneto (1975); Lombardía (1975); Abruzzo (1982); Lazio (1983); Molise (1983); Piamonte (1989); Friuli-Venezia Giulia (1991); Valle d'Aosta (1992); Toscana (1993); Emilia-Romagna (1995). 
deportivas ${ }^{36}$; $y$ entre las segundas, el ejercicio de la potestad disciplinaria deportiva que, por su naturaleza de función pública delegada, las decisiones de los Comités Disciplinarios Federativos, agotada la vía federativa, son susceptibles de recurso ante la propia Administración, si es en el Estado ante el Tribunal Administrativo del Deporte, y en el ámbito autonómico ante el Tribunal Administrativo del Deporte o Comité de Disciplina Deportiva de la Consejería competente en materia de deportes.

Ciñéndonos al ejercicio de la potestad disciplinaria deportiva ${ }^{37}$, en el ámbito del Estado, el artículo 6.2.c del Real Decreto 1591/1992, de 23 de diciembre, sobre Disciplina Deportiva, dispone que el ejercicio de la potestad disciplinaria corresponderá: " a las federaciones deportivas españolas sobre todas las personas que forman parte de su propia estructura orgánica; sobre los clubes deportivos y sus deportistas, técnicos y directivos; los jueces y árbitros, y general, todas aquéllas personas y entidades que, estando federadas, desarrollan la actividad deportiva correspondiente en el ámbito estatal".

Igualmente, sirva el ejemplo de Andalucía, aplicable a cualquier otra Comunidad Autónoma de acuerdo con sus respectivas normas, en el caso de Andalucía la Ley 5/2016, de 19 de julio, del Deporte de Andalucía, su artículo 124.1.b) sobre el ejercicio de la potestad disciplinaria, le corresponde las federaciones deportivas andaluzas: "sobre las personas y entidades integradas en las mismas, incluyendo a estos efectos a los clubes deportivos andaluces, y sus deportistas, personal técnico y directivo, jueces y árbitros y, en general, todas aquellas personas o entidades que de forma federada desarrollan la modalidad deportiva correspondiente en el ámbito de la Comunidad Autónoma", desarrollado por el decreto 205/2018, de 13 de noviembre, por el que se regula la solución de litigios deportivos en la Comunidad Autónoma de Andalucía, cuyo artículo 24.1.b) reproduce los mismos términos.

36 Los vigentes Estatutos de la Real Federación Española de Deportes de Invierno, aprobados en Asamblea General el 31 de octubre de 2009 (última modificación de 2015) y por la Comisión Directiva del Consejo Superior de Deportes el 18 de diciembre de 2009, establecen en su artículo $1^{\circ}$, que la citada Federación está integrada por las Federaciones de ámbito autonómico, clubes, deportistas, jueces, técnicos y otros colectivos interesados que practiquen o contribuyan al desarrollo de los deportes objeto de su competencias; las especialidades deportivas $\left(\right.$ art. $3^{\circ}$ ) cuya promoción y desarrollo compete a la RFEDI son: a) esquí alpino, esquí de fondo, biathlon, saltos de esquí, Freestyle (estilo libre), snowboard, Telemark, trineo con perros y pulka escandinava y combinada nórdica y esquí de velocidad,

37 Véase el trabajo coordinado por MILLÁN GARARIDO, A., El régimen sancionador del deporte en Andalucía. Potestad Sancionadora y Potestad disciplinaria en la Ley 6/1998, del deporte, Bosch, Barcelona, 1999.

GAMERO CASADO, E., "Los procedimientos sancionadores federativos en la legislación deportiva andaluza", en Anuario Andaluz de Derecho Deportivo, núm. 2(2002), pp. 123-143; GARCÍA CABA, M., "sobre la eficacia de la normativa de las federaciones deportivas andaluzas", en Anuario Andaluz de Derecho Deportivo, núm. 5 (2005),pp. 49-76; DE LA IGLESIA PRADOS, E., "Las infracciones disciplinarias en la Ley del Deporte de Andalucía", en Anuario Andaluz de Derecho Deportivo, núm. 4 (2004), pp. 111-136. 
Así las cosas, el ejercicio de la potestad disciplinaria de una federación deportiva sólo puede ejercerse sobre una persona física o jurídica que tenga la condición de federado, y ello se adquiere al tener en vigor una licencia deportiva, para la participación en actividades o competiciones oficiales (art. 7 RD. 1835/1991).

Sin embargo, la nueva legislación deportiva autonómica, establece otra forma de vincularse a una federación deportiva como es a través del título habilitante, es el caso del artículo 24.4 de la Ley 5/2016, cuando permite que las federaciones deportivas pueden expedir otros títulos habilitantes para participar en competiciones deportivas no oficiales y en actividades de deportes de ocio siempre que lo prevean sus estatutos.

Estos planteamientos son lógicos, si tenemos en cuenta qué hasta poco, las leyes y reglamentos en materia de deporte, tenían por objeto la regulación del deporte de competición oficial. Sin embargo, en la última década, con el desarrollo de la actividad deportiva no competitiva oficial las Administraciones se han dado cuenta que hay un sector más numeroso en la práctica del deporte que el llamado oficial ${ }^{38}$, son ejemplos muy gráficos; la natación, el ciclismo de ruta, la bicicleta de montaña, el esquí, el senderismo, la espeleología, la hípica, etc., donde los practicantes no federados son la mayoría, piénsese en un domingo los ciclistas que hay por los montes y las carreteras al margen de cualquier organización federativa, o los miles de senderistas que salen a la montaña o al mar, por citar algunos ejemplos.

Como hemos expuesto anteriormente, las nuevas leyes autonómicas del deporte, esto es las que podemos llamar de segunda generación (Andalucía, Aragón, Canarias...), sí han recogidos en sus planteamientos esta forma de practicar el deporte, como es el caso, de la citada y comentada Ley 5/2016, de 19 de julio, del Deporte de Andalucía, que incorpora el deporte de ocio (art. 4.d), al que corresponde todo tipo de actividad física que se realice en una organización o al margen de ésta, y está dirigida a cualquier objetivo no competitivo, relacionados con la salud, algunos hábitos deportivos, así como la ocupación del tiempo libre; incluyendo en el artículo 10, el deporte en el medio natural tal como hemos visto anteriormente.

El caso del esquí y sus especialidades, constituye un ejemplo muy concreto y relevante de estos planteamientos, pues frente a los 6.000.000 millones de jornadas anuales de esquí (datos que ofrece la Asociación Turística de Estaciones de Esquí

38 La propia WEB del Consejo Superior de Deportes, www.csd.gob.es 4/los deportes-más-practicados; lo dice todo, en el análisis de los deportes más practicados: 4 . El desfase entre el deporte federado y el deporte popular y recreativo, y sobre los 21 deportes que más practican los españoles, nos encontramos en la primera posición la natación con un 33\% de practicantes, donde el 98\% de practicantes lo hace fuera del sistema federado; o el ciclismo en tercer lugar con 19.1\%, de los $18.7 \%$ no están federados y de los que sólo el $0.4 \%$, lo están. 
Montaña ATUDEM a 2017), las licencias de las modalidades y especialidades que integran la Federación de Deportes de Invierno, son muy poco relevantes 3742 licencia a nivel nacional con 390 clubes, mientras que en el caso concreto de Andalucía son 390 deportistas y 19 clubes, lo que a nivel nacional sitúa a esta Federación Española en el puesto número 62 de 88 federaciones deportivas.

En definitiva, el nuevo modelo en las Comunidades Autónomas, apuesta por la incardinación de la práctica deportiva en el modelo federativo, de carácter no competitivo oficial, como sucede en deportes como la caza, donde hemos visto como la mayoría de los cazadores no participan en competiciones deportivas oficiales, y sí en la práctica deportiva, normalmente dentro de una sociedad de cazadores y en un coto determinado; por el contrario, muy pocos son los participantes en campeonatos oficiales de caza menor o caza mayor, según las diferentes actividades, esto supone que de las 326140 licencias deportivas a nivel nacional y 89461 en Andalucía (datos WEB CSD a 2017), no están relacionadas con la competición oficial federativa y sí con la práctica por placer, ocio, recreación, etc.

Igualmente, en apoyo de todos estos planteamientos, tenemos también el caso del Golf, del que da buena cuenta el arquitecto y urbanista USLÉ ÁLVAREZ ${ }^{39}$, quien se muestra totalmente decidido por la licencia administrativa: "Hoy día en el golf es impensable que una persona se compre en el Corte Inglés unos palos de golf, se meta en un campo de golfy se lie a pelotazos con todo el que pase por ahi, es impensable. Cualquiera que haya jugado al golf sabe que tiene que pasar unos requisitos, y uno de ellos es meterse en un green, empezar a darle palos hasta que el profesor o el encargado que tiene el campo le diga que tiene una licencia, en este caso licencia federativa, y que con esa licencia ya puede él seguir. ¿Esa licencia que le hace? Pues que conoce las reglas del juego, las reglas del campo, las reglas de seguridady que es capaz de circular por un campo. Bueno, pues el esqui, que es mucho más siniestrable que el golf no sucede eso, cualquiera se monta en unos esquís, que los alquila, se monta en una pista, que no sabe ni como es, si está helada, si está dura, si está blanda, se tira por una pendiente y se lleva por delante al primero que sale por ahi, o se mata".

Por todo esto, para evitar los miles de situaciones que se presentan en las pistas de esquí, este arquitecto considera que es necesario y perfectamente posible qué para sacar el forfait, cuando una persona va a la taquilla, exista un permiso administrativo que haya otorgado un determinado organismo, para que esa persona conozca las reglas del usuario y no provoque colisiones y conflictos, licencia administrativa que se sacaría en los campos de principiantes.

39 USLE ÁLVAREZ, J., Informe de la Ponencia de estudio sobre el uso racional de las Estaciones de Esquí, Dirección de Estudios y Documentación, Departamento de Publicaciones, Secretaría General del Senado, Madrid, 2006, pp. 154-155. 
De esta misma línea de opinión es ROLDAN OSÉS ${ }^{40}$, quien argumenta desde cualquier punto de vista, surge la necesidad de controlar y ordenar los deportes de invierno y las estaciones de esquí: "Se puede entender que en mi opinión una licencia o tarjeta federativa obligatoria resolvería muchos de los problemas a los que estamos aludiendo, ya que el usuario constituye el sujeto pasivo de toda nuestra preocupación. Que cada persona que practique deportes de invierno que, al fin y al cabo, son deportes de riesgo, sea portador de una acreditación, se llame tarjeta o licencia federativa, resolvería las cuestiones sobre responsabilidad, cobertura en caso de accidente, ventajas administrativas y económicas y la fuente de financiación más legítima para los planteamientos básicos de interés público de los deportes de invierno".

Estando totalmente de acuerdo estos planteamientos, nos quedamos con la necesidad de tener una licencia administrativa, en este caso, la licencia deportiva o título habilitante expedido por una federación, sin entrar en la posible regulación de los requisitos para obtenerla, sobre todo en aquellos de carácter técnico, que podrían dificultar la propia práctica del deporte; aunque no estaría nada mal que, como requisito, se exigiese acreditar algunos conocimientos sobre las normas de conducta y comportamiento, como sucede en el ámbito de la caza donde para obtener la licencia se ha de superar en la Consejería competente en materia de medio ambiente un examen $^{41}$, por el que el aspirante a cazador demuestre conocimientos en materia de especies, vedas, períodos de caza, etc., cuya superación, es requisito imprescindible para obtener las demás licencias, dando lugar a la inscripción en un Registro de cazadores.

En todo caso, la licencia deportiva o el título habilitante para la práctica del esquí y sus especialidades, posibilitaría un medio eficaz para la prevención de accidentes y seguridad en las pistas de esquí, ante los actos ocasionados por otros esquiadores que, han incumplido las normas de conducta, mediante un procedimiento similar al que sucede en el ámbito deportivo, donde una vez detectada la infracción, el árbitro o juez de la contienda, aplica la sanción disciplinaria deportiva, de acuerdo con las reglas de juego, (exclusión, descalificación, expulsión, técnica, etc.). Para posteriormente, rellenar el acta -en este caso pliego de cargo- con las incidencias que se han producido, entregando una copia al infractor, con lo que se considera evacuado el trámite de audiencia para que alegue lo que estime más oportuno en su defensa, y procedan los Comités disciplinarios federativos, de acuerdo con sus normas reglamentos disciplinarios aprobados por la Administración, a aplicar la correspondiente sanción deportiva, con las garantías del procedimiento disciplinario.

40 ROLDAN OSES, E., presidente de la Real Federación Española de Deportes de Invierno, (2006:83).

41 En el caso de Andalucía, es la Orden de 31 de marzo de 1998 de la Consejería de Medio Ambiente, sobre programas de materias y regula la organización de los exámenes y cursos del cazador y del pescador. 
Obviamente, todas estas actuaciones, deben de ajustarse al principio de legalidad que constitucionalmente se exigen, a través de una Ley nueva, ya hemos vistos las dificultades para que el legislador acometa la tarea, o bien incorporando a las ya existentes en materia de deporte, un nuevo título "De la práctica y seguridad del esquí y sus especialidades".

Con este modelo que se propone, todos los esquiadores deberán estar en posesión de una licencia o título habilitante expedido por una federación deportiva dutonómica, que le permita realizar su práctica en cualquier estación de esquí. Estableciendo para ello, el reconocimiento mutuo a través de convenios federativos, o en el marco de la federación española; y no, como sucede, en otras modalidades deportivas la caza, por ejemplo, donde se exige la licencia autonómica de la federación deportiva territorial para practicar la modalidad deportiva, en el ámbito de cada Comunidad Autónoma.

En la misma norma legal sobre la práctica del esquí, participamos del criterio mayoritario de otorgarles las funciones de control, vigilancia y represión a los "pisteros socorristas", quienes tendría la habilitación a través de un curso específico que las federaciones deportivas realizaran de forma periódica, como sucede con los cursos de árbitros y jueces deportivos, de acuerdo con las condiciones y requisitos que se pacten con las entidades gestoras de las Estaciones de esquí. No olvidemos que estas personas son empleados de estas empresas, las cuales, en definitiva, serán las que establezcan las condiciones laborales para el desempeño de estas funciones.

Ahora bien, al tratarse de entidades totalmente distintas; por un lado, los gestores de las estaciones de esquí, como entidades mercantiles; de otro, las federaciones autonómicas, como entidades deportivas sin ánimo de lucro, habría que buscar un mecanismo de recepción de los efectos que podrían tener las sanciones federativas en la estación de esquí para que, una vez que el deportista ha sido sancionado, pueda cumplir con la sanción (supongamos un período de tiempo concreto), lo que se llevaría a la práctica a través de un Convenio de colaboración entre ambas entidades, donde la primera se comprometen a aceptar la licencia federativa o título habilitante, como requisito imprescindible para autorizar la expedición del forfait; y las segundas, para realizar los cursos de formación y el ejercicio de la potestad disciplinaria. Por supuesto, todo esto, es independiente de las competencias que las Fuerzas y Cuerpos de Seguridad tienen atribuidas en materia de orden público, cuando se produzcan incidentes de esta naturaleza en las pistas de esquí.

A la hora de modular los requisitos de la licencia federativa, se debe de imponer los razonamientos moderados entre los gestores de las Estaciones y las federaciones deportivas, en base a la lealtad mutua entre las entidades colaboradoras, por lo que la tarjeta federativa -licencia o título habilitante- debe de reunir unos requisitos, mí- 
nimos e imprescindibles, con un precio que, federativamente les va a venir muy bien, pero que no debe de estar alejado de los precios normales en el ámbito federativo.

De la misma manera, para evitar que la propia entidad deportiva vea desvirtuados sus fines competitivos, ante el aluvión de nuevas licencias, lo que daría lugar al ejercicio, entre otros, de los derechos electorales, no existiría impedimento alguno en que esta licencia se diferencie de las licencias de "competición oficial", con lo que el voto puede ser limitado porcentualmente, así como los seguros que debe de llevar, donde recordamos que ya la ponencia del Senado, en su recomendación número 9a, formuló la siguiente: "Exigir con carácter universal a los usuarios de las estaciones de esquí un seguro obligatorio de responsabilidad civil que se incorpora al forfait", en nuestro caso, a la licencia o título habilitante.

El aseguramiento deportivo, se nos presenta como un escoyo muy importante, la razón no es otra que su establecimiento eleva, o mejor dicho puede elevar, el coste de la tarjeta deportiva, sin olvidar que los seguros deportivos ${ }^{42}$ presentan un régimen que no es precisamente un ejemplo de homogeneidad, pues en el Derecho positivo el aseguramiento deportivo se encuentra esparcido por un sinfín de disposiciones, principalmente de rango reglamentario, diseminadas en ámbito específicos que, a veces se solapan y a veces se complementan, lo que según GAMERO CASADO ${ }^{43}$, se trata de una dispersión normativa que difumina la percepción del conjunto, corriendo el riesgo de ignorar el nivel real de protección que, para los propios deportistas, para los organizadores o participantes o para terceros depara en la actualidad el ensamblaje de los seguros obligatorios regulados en las normas sectoriales.

No obstante, la seguridad y la práctica de los deportes de invierno, no se puede limitar a una tarjeta federativa y a su inclusión en el régimen disciplinario deportivo de una Federación, pues lógicamente para cumplir estos objetivos de seguridad, también las estaciones de esquí, más concretamente las empresas gestoras de las mismas, deben de ser exigentes con la normativa que debe de contemplar la Ley de la que venimos hablando.

Por lo que también pueden ser objeto de sanción, en caso de incumplimiento, de todo lo que es de su responsabilidad: clasificación de pistas, preparación, balizamiento, pisado, señalización, protección, información, apertura, cierre, etc., de tal manera que, cuando las gestoras sean responsable de una infracción, en estos supuestos, la Administración autonómica active el procedimiento sancionador al que estarían sometidas, no el de carácter disciplinario deportivo que se aplicaría a los practicantes.

42 JIMÉNEZ SOTO, I, "La responsabilidad deportiva y su aseguramiento", en E. GAMERO CASADO (coord.) Fundamentos de Derecho Deportivo, Tecnos, Madrid, 212, pp. 291-294.

43 Véase su obra imprescindible en la materia, GAMERO CASADO, E., Los seguros deportivos obligatorios, Bosch, Barcelona, 2003. 
Efectivamente, por lo que afecta a las estaciones de esquí, no son sujetos pasivos de la potestad disciplinaria deportiva, pero si son en el ámbito de la potestad sancionadora de la Administración deportiva, como sería la Consejería competente en materia de deporte, como podemos apreciar, nuevamente a título de ejemplo con el ordenamiento jurídico de Andalucía, en los artículos 122 a 120 de la Ley 5/2016.

\section{CONSIDERAGIONES FINALES}

$1^{a}$ El aumento cada día de deportistas que eligen el medio natural en general para realizar su actividad y, en particular los ENP, como lugar preferido para realizar su actividad deportiva, convirtiéndose por sus conocimientos del medio ambiente en un usuario cualificado, constituyen un argumento poderoso para reclamar su mayor participación en las Juntas Rectoras de los Parques Naturales, los Patronatos de los Parques Nacionales y los Consejos de Participación.

$2^{a}$ Está demostrado que el anonimato es uno de los elementos más relevantes para que las personas puedan realizar actos incívicos en el medio natural, por supuesto en los ENP; por lo que, una forma adecuada de eliminar posibilidades a los depredadores ambientales humanos, consiste en la identificación para acceder al lugar, lo cual se ve ampliamente facilitado por la clásica licencia deportiva, a la que hay que unir "el título, habilitante" o tarjeta federativa para los deportistas que no participan en competiciones oficiales, como son las actividades de ocio.

Elemento fundamental que acompaña a numerosas actividades en el medio natural, tan alejadas de la competición oficial: senderismo, escalada, espeleología, descenso de barrancos, piragüismo, esquí y sus especialidades, hípica, etc. Razón fundamental para que las federaciones deportivas se conviertan en entidades colaboradoras de la protección del medio ambiente, al igual que hemos podido apreciar en las funciones de homologación de los senderos en diferentes Comunidades Autónomas.

$3^{\text {a }}$ La inclusión por vía reglamentaria entre las funciones públicas delegadas de las federaciones deportivas de la protección del medio ambiente a través de las actividades deportivas y la seguridad de la práctica del deporte en el medio natural, podría tener como consecuencia las siguientes actuaciones:

a) El compromiso de las federaciones deportivas de adoptar un Código de Conducta en materia de medio ambiente, para que todo poseedor de licencia deportiva o título habilitante, la acepte como requisito ineludible para su expedición.

b) La posibilidad de realizar determinadas actividades deportivas en zonas prohibidas, al pasar a actividades reguladas por los órganos de gestión del ENP, 
controladas por las federaciones deportivas dentro de los términos establecidos en el Convenio de Cooperación. Por ejemplo, en determinados días y en concretas horas, e incluso con un número específico de practicantes, se habilita la práctica de la bicicleta de montaña, que pasa a ser controlada por el ente federativo, con sus prescripciones técnicas, con la posibilidad de aplicar el régimen disciplinario deportivo a los participantes en dicha actividad, sin perjuicio de las responsabilidades en materia sancionadora a que dieran lugar determinadas conductas.

c) En relación al apartado anterior, las federaciones deportivas siguiendo los criterios de los órganos de gestión de los ENP, se comprometerían a incluir en sus Reglamentos de Régimen Disciplinario Deportivo, la tipificación de conductas contrarias a la protección medio ambiente y la seguridad de la práctica deportiva en el medio natural, como infracciones y sus correspondientes sanciones.

$4^{\text {a }}$ En definitiva adoptar entre las medidas de control de las actividades en los ENP, la colaboración de los entes federativos, se aleja de los tradicionales mecanismos de intervención pública de control o policía, para adoptar los modernos mecanismos de autorregulación regulada.

Desde el momento, en un principio, en que son normas que requieren la previa aceptación de los sujetos privados y que no son exigibles más allá del círculo de sujetos que convienen en su aceptación, para posteriormente ser incorporados por la vía del Convenio al ordenamiento jurídico, como puede ser su incorporación al Plan Rector de Uso y Gestión, adquiriendo la condición de normas de Derecho objetivo, de obligada observancia y que se toman como referencia por los poderes públicos, Administraciones y Tribunales.

$5^{\text {a }}$ La necesidad de que las Leyes de Senderos de las Comunidades Autónomas, declaren la utilidad pública de los senderos principalmente mediante declaración genérica en ley sectorial, para de esta forma posibilitar la expropiación forzosa de la Administración respectiva, cuando el sendero se corta, se interrumpe, finaliza, etc., por encontrarse con una finca privada. Mientras tanto, se debería de activar el mecanismo previsto en el artículo $1^{\circ}$ LEF de la declaración implícita en todos los Planes de Obras y Servicios.

$6^{\text {a }}$ Ante la inexistencia de una Ley que garantice la seguridad de la práctica del esquí y sus especialidades, demandada por los responsables de las estaciones de esquí y montaña a través de ATUDEM, se plantea la posibilidad de establecer un mecanismo de régimen disciplinario deportivo, a través de la licencia deportiva o del título habilitante, para la práctica de estas actividades deportivas, en el ejercicio de las funciones públicas delegadas, en materia de protección de medio ambiente y de la seguridad de la práctica del deporte en el medio natural. 


\section{BIBLIOGRAFÍA}

AGUIRREAZKUENAGA ZIGORRAGA, I.: Intervención pública en el deporte, IVAP-Civitas, Madrid, 1998.

BERMEJO VERA, J.: "Constitución y Ordenamiento deportivo", en Revista Española de Derecho Administrativo, núm. 63 (1989), pp. 337 y ss.

-"La dimensión constitucional del Derecho de Asociación, Revista de Administración Pública, núm. 136, (1995), pp. 119 y ss.

-Constitución y Deporte, Tecnos, Madrid, 1999.

-Derecho Administrativo Básico. Parte Especial, Volumen II, Civitas, Cizur Menor, 2017.

BRUCGOLERI, C., "Ordinamento sciitistico italiano", en I Forumn Jurídico Europeo de la nieve, "Dai diritti della neveal Diritto della neve", en Professione de Montagna, núm. 85 (2006).

CHIEPPA, R, y DELLANTONIO, M., "La nouva legge sullo sci: regole di comportamiento e responsabiltá nelle aree sciabili lo sci alpino, lo sci fuoropista e le competenze nell' attivittá di prevenzione valanghe”, en Diritto e formazzione,núm. 2 (2005), p. 178.

CONDE ANTEQUERA, J:: "Instrumentos públicos de protección ambiental (II): El control administrativo de la implantación y puesta en funcionamiento de las actividades con incidencia ambiental" en Derecho Ambiental Adaptado al EEES, dir. TORRES LÓPEZ, M.A., Y ARANA GARCÍA, E., Tecnos Madrid, pp.92-103.

DE LA IGLESIA PRADOS, E.: "Las infracciones disciplinarias en la Ley del Deporte de Andalucía", en Anuario Andaluz de Derecho Deportivo, núm. 4 (2004), pp. $111-136$.

ESTEVE PARDO, J.:" Las asociaciones deportivas de configuración legal. El caso de las federaciones deportivas", en Revista Española de Derecho Administrativo, núm. 45 (1985), pp. 113 y ss.

-Derecho del Medio Ambiente, Marcial Pons, Madrid, 2008.

-Lecciones de Derecho Administrativo, (séptima edición), Marcial Pons, Madrid, 2017, pp. 83-87.

FUERTES LÓPEZ, M.: Asociaciones y Sociedades Deportivas, Marcial Pons, Madrid, 1992. 
GAMERO CASADO, E.: "Los procedimientos sancionadores federativos en la legislación deportiva andaluza", en Anuario Andaluz de Derecho Deportivo, núm. 2(2002), pp. 123-143.

- Los seguros deportivos obligatorios, Bosch, Barcelona, 2003.

JIMÉNEZ SOTO, I.: "El difícil anclaje jurídico de las actividades deportivas en los espacios naturales protegidos, a través de los instrumentos de ordenación", libro homenaje profesor RAFAEL BARRANCO VELA, coord. BALAGUER CALLEJÓN, F y ARANA GARCÍA, E, Vol.II, Civitas Thomson Reuters, Madrid, 2014, pp. 1990-2012.

-La configuración jurídica del deporte en el medio natural. Relaciones con el turismo, el desarrollo sostenible y la ordenación del territorio, Reus, Madrid, 2015.

-"Actividad deportiva en el medio natural", en Comentarios a la nueva ley del Deporte de Andalucía”, dir. MILLÁN GARRIDO, A.: Reus, Madrid, pp.156-168.

LOBO RODRIGO, A.: La ordenación y gestión de playas: especial referencia a los usos turístico-deportivos, Tirant Lo Blanch, Valencia, 2016.

LÓPEZ MENUDO, F.: "Concepto de medio ambiente y reparto competencial", en Derecho ambiental de Andalucia”, dir. VERA JURADO, D., Tecnos, Madrid, 2005, pp 31-46.

LÓPEZ RAMON, F.: Política ecológica y pluralismo territorial. Ensayo sobre los problemas de articulación de los poderes públicos por la conservación de la biodiversidad, Marcial Pons, Madrid, 2009.

MILLÁN GARARIDO, A.: El régimen sancionador del deporte en Andalucía. Potestad Sancionadora y Potestad disciplinaria en la Ley 6/1998, del deporte, Bosch, Barcelona, 1999.

NASARRE SARMIENTO, J,M.: Senderismo 100 hitos normativos para pensar, Desnivel, Madrid, 2016.

- OLMEDO GAYA, A.: "La expropiación forzosa", en Conceptos para el estudio del Derecho Administrativo II en el Grado, Coordinadora TORRES LÓPEZ, M,A., Tecnos, quinta edición, Madrid, 2017, pp.143-166.

PORRAS LIMA, F.: "Derecho Deportivo y Derecho turístico: surgimiento, desarrollo y consolidación del turismo activo en España", en El Derecho Deportivo en España 1975-2005, dir. JIMÉNEZ SOTO I. y ARANA GARCÍA, E., Consejería de Turismo y Deporte de la Junta de Andalucía, Sevilla, 2005, pp. 317-348.

RIVERO YSERN, J,L.: Manual de Derecho Local, $6^{\text {a }}$ edición, Civitas, Madrid, 2010. 
SÁnCHEZ MORÓN, M.: Derecho Administrativo. Parte General, Civitas, Madrid, 2010, pp. 639-670.; 2018, pp.758-760.

TORRES LÓPEZ, M,A.:'La responsabilidad patrimonial de las Administraciones Públicas", en Conceptos para el estudio del Derecho Administrativo en el Grado, Tecnos, cuarta edición, Madrid, 2017, p.128.

USLE ÁlVAREZ, J., Informe de la Ponencia de estudio sobre el uso racional de las Estaciones de Esquí, Dirección de Estudios y Documentación, Departamento de Publicaciones, Secretaría General del Senado, Madrid, 2006, pp. 154-155. 